Published in final edited form as:

Nat Rev Dis Primers. ; 4(1): 50. doi:10.1038/s41572-018-0047-y.

\title{
Polycystic kidney disease
}

\section{Carsten Bergmann ${ }^{1,{ }^{*}}$, Lisa M. Guay-Woodford ${ }^{2}$, Peter C. Harris ${ }^{3}$, Shigeo Horie ${ }^{4}$, Dorien J. M. Peters ${ }^{5}$, and Vicente E. Torres ${ }^{3}$}

${ }^{1}$ Department of Medicine, University Hospital Freiburg, Freiburg, Germany. ${ }^{2}$ Center for Translational Science, Children's National Health System, Washington, DC, USA. ${ }^{3}$ Division of Nephrology and Hypertension, Mayo Clinic, Rochester, MN, USA. ${ }^{4}$ Department of Urology, Juntendo University Graduate School of Medicine, Tokyo, Japan. ${ }^{5}$ Department of Human Genetics, Leiden University Medical Center, Leiden, Netherlands.

\section{Abstract \\ Cystic kidneys are common causes of end-stage renal disease, both in children and in adults. Autosomal dominant polycystic kidney disease (ADPKD) and autosomal recessive polycystic kidney disease (ARPKD) are cilia-related disorders and the two main forms of monogenic cystic kidney diseases. ADPKD is a common disease that mostly presents in adults, whereas ARPKD is a rarer and often more severe form of polycystic kidney disease (PKD) that usually presents perinatally or in early childhood. Cell biological and clinical research approaches have expanded our knowledge of the pathogenesis of ADPKD and ARPKD and revealed some mechanistic overlap between them. A reduced 'dosage' of PKD proteins is thought to disturb cell homeostasis and converging signalling pathways, such as $\mathrm{Ca}^{2+}$, cAMP, mechanistic target of rapamycin, WNT, vascular endothelial growth factor and Hippo signalling, and could explain the more severe clinical course in some patients with PKD. Genetic diagnosis might benefit families and improve the clinical management of patients, which might be enhanced even further with emerging therapeutic options. However, many important questions about the pathogenesis of PKD remain. In this Primer, we provide an overview of the current knowledge of PKD and its treatment.}

\footnotetext{
* carsten.bergmann@hotmail.com; carsten.bergmann@uniklinik-freiburg.de. Author contributions

Introduction (C.B.); Epidemiology (S.H.); Mechanisms/pathophysiology (D.J.M.P. and L.M.G.-W.); Diagnosis, screening and prevention (P.C.H. and C.B.); Management (V.E.T.); Quality of life (S.H.); Outlook (P.C.H.); Overview of Primer (C.B.)

Competing interests

C.B. is an employee of Bioscientia/Sonic Healthcare and holds a part-time faculty appointment at the University of Freiburg, Germany.

Publisher's note

Springer Nature remains neutral with regard to jurisdictional claims in published maps and institutional affiliations.

Reviewer information

Nature Reviews Disease Primers thanks J. Calvet and the other anonymous reviewer(s) for their contribution to the peer review of this work.

RELATED LIKS

ADPKD Mutation Database (PKDB): http://pkdb.mayo.edu/ Genome aggregation database (gnomAD): http:// gnomad.broadinstitute.org/
} 
In patients with polycystic kidney diseases (PKDs), the kidneys contain multiple fluid-filled cysts, although other organs may also be affected (FIG. 1). Although PKD is inherited monogenically, it is phenotypically, genically and allelically heterogeneous. Autosomal dominant PKD (ADPKD) is the most common form of PKD and is generally an adult-onset, multisystem disorder that is characterized by gradually growing renal cysts that start to develop in utero and can originate from all areas of the kidneys, although cysts usually form in the distal regions of the nephron and the collecting duct. Progressive fibrocystic renal disease in ADPKD is often accompanied by hepatobiliary changes or other extrarenal abnormalities, such as intracranial arterial aneurysms ${ }^{1,2}$. Mutations in PKD1 or PKD2, which encode polycystin 1 (PC1) and PC2, respectively, are the most common cause of ADPKD. PC1 and PC2 form a heterodimeric complex through the interaction of the coiledcoil motifs in the carboxy-terminal tails of each protein, which likely functions at primary cilia. PC2 is a cation channel that is a member of the transient receptor potential (TRP) family of ion channels, which are ubiquitously present across evolution and usually contain six membrane-spanning helices that are flanked by an intracellular amino terminus and carboxyl terminus (FIG. 2). By contrast, the roles of PC1 and the PC1-PC2 complex are only poorly understood. Autosomal recessive PKD (ARPKD) is rarer, and the clinical course is usually much more severe than with ADPKD. ARPKD typically manifests perinatally or in childhood, and patients often die perinatally or in infancy. Manifestations of the disease include hepatic fibrosis and greatly enlarged kidneys, and cysts typically affect the collecting ducts. ARPKD is primarily caused by mutations in polycystic kidney and hepatic disease 1 (PKHD1), which encodes fibrocystin (also known as polyductin), a protein that localizes to the primary cilium and basal body.

Although single renal cysts are common and usually benign in adults, bilateral cystic kidneys require careful clinical assessment to identify the underlying genetic disorder, especially in children, owing to major implications for the patient and family. Both ADPKD and ARPKD often result in chronic kidney disease (CKD; a gradual loss of kidney function) and end-stage renal disease (ESRD; severe kidney disease that requires dialysis or kidney transplantation for patient survival), which are associated with substantial associated morbidity and mortality.

In the past decade, progress has been made in unravelling the aetiology of PKD. Studies have shown that the proteins encoded by genes associated with PKD colocalize in multimeric complexes at distinct subcellular sites in epithelial cells, and compelling evidence exists to suggest that primary cilia have a central pathogenic role in $\mathrm{PKD}^{3-5}$. Cell biological and clinical research approaches have further extended our understanding of the pathophysiology of PKD and are starting to help in the identification of rational personalized therapies.

In this Primer, we provide a general overview of the current knowledge of ADPKD and ARPKD, including the epidemiology, pathophysiology, prevention, prognosis and quality of life (QOL). Furthermore, we discuss the diagnostic approaches and the clinical management of PKD and its comorbidities in greater detail. Finally, we provide a brief outlook and discuss potential future therapeutic options. 


\section{Epidemiology}

\section{ADPKD}

ADPKD is the most common potentially lethal (that is, it results in renal failure and death in the absence of renal replacement therapy (RRT)) single-gene disorder and the most prevalent inherited progressive kidney disease ${ }^{2}$. The prevalence of ADPKD is reported to be between 1 in 400 and 1 in 1,000 live births, mainly on the basis of two early landmark clinical studies, in Denmark ${ }^{6}$ and in Minnesota, USA 7 . On the basis of this prevalence, ADPKD is predicted to affect $>10$ million people worldwide in all ethnic groups and therefore constitutes a major public health burden.

To ascertain the exact prevalence of a hereditary disease, several factors must be considered ${ }^{8}$ - the geographic and ethnic composition and the size of the population, the choice and mode of calculation of epidemiologic measurement, the screening policies and other characteristics of the health-care system, the disease definition and diagnostic criteria that are used, the sources of ascertainment and possible causes of under-ascertainment and the period of time during which events are counted (ascertainment period). Thus, variability in study design and ascertainment might partially explain the large differences in estimates of the prevalence of ADPKD that have been reported in some studies. For example, two clinical surveys in Europe (carried out in the United Kingdom ${ }^{9}$ and in France ${ }^{10}$ ), as well as a survey in the Seychelles ${ }^{11}$ measured the prevalence of symptomatic individuals and estimated the prevalence of asymptomatic individuals. The estimated prevalence of ADPKD was 1 in 2,459 in the UK study, 1 in 1,111 in the French study and 1 in 542 for the Seychelles. In the study of the Seychelles population, the researchers speculated that the high prevalence among white individuals might be due to a founder effect (that is, low genetic variation in a population because it was started by a small number of individuals).

Subsequent studies based on renal phenotypic features reported an ADPKD prevalence of 1 in 2,700 to 1 in 4,000 in different populations in Europe and Japan ${ }^{12-15}$. A recent study on ADPKD prevalence in the European Union, which reviewed the epidemiology literature from 1980 to 2015 and was based mainly on the large Registry of the European Renal Association (ERA)-European Dialysis and Transplant Association (EDTA), estimated that the prevalence of ADPKD in 19 countries was 1 in 2,525 (REF. ${ }^{16}$ ); that is, fewer than 5 cases in 10,000, which is the threshold for a rare disease in the European Union.Importantly, the prevalence rates estimated in all these studies were much lower than the ADPKD prevalence estimated from autopsy studies ( $\geq 1$ in 500 $)^{6,7,17}$. These data suggest that marked under-ascertainment exists and that a considerable number of (probably only mildly or moderately) affected individuals remain undiagnosed ${ }^{18}$.

ADPKD is an important cause of ESRD, for which patients receive RRT, which includes haemodialysis, peritoneal dialysis, haemofiltration, haemodiafiltration and kidney transplantation. In a population-based registry in Germany, 32\% of patients with ADPKD were receiving $\mathrm{RRT}^{14}$. ESRD occurs as a result of ADPKD in up to $75 \%$ of patients by 70 years of age ${ }^{14,19-21}$. Age-adjusted sex ratios suggest that ADPKD is more progressive in men than in women (1.2-1.3 men to women) on the basis of rates of ESRD. A Canadian study reported that $25 \%$ of patients with ADPKD had ESRD by 47 years of age, $50 \%$ by 59 
years of age and $75 \%$ by 70 years of age ${ }^{22}$. In a French study, $22 \%$ of patients with ADPKD had ESRD by 50 years of age, $42 \%$ by 58 years of age and $72 \%$ by 73 years of age ${ }^{23}$. A European study of $>300,000$ patients starting RRT between 1991 and 2010 reported that the age-adjusted and sex-adjusted incidence of RRT in patients with ADPKD increased slightly over the study period from 7.6 per million to 8.3 per million population ${ }^{24}$. The researchers in this study noted that the incidence of RRT had markedly increased over time in patients $>70$ years of age, whereas no change was observed for the cohort of patients with ADPKD who were $<50$ years of age, suggesting that older patients are receiving RRT. In the UK Renal Registry, mortality in patients with ADPKD receiving RRT was 3.18-4.96 per 100 personyears, which was lower than that of patients receiving RRT who had other renal diseases.

The ADPKD group had a lower hazard for all-cause mortality than the other renal diseases group (adjusted HR 0.45, 95\% CI 0.38-0.53) ${ }^{25}$. Cardiac diseases and infections were the leading causes of death in patients with ADPKD who received RRT ${ }^{24}$.

\section{ARPKD}

As ARPKD is much rarer than ADPKD, the available epidemiological data for ARPKD are not as extensive as those for ADPKD. The reported incidence of ARPKD in North, Central and South America is 1 in 26,500 live births, corresponding to a carrier frequency of $\sim 1$ in 70 in non-isolated populations ${ }^{26}$. Isolated or inbred populations with many consanguineous marriages might have a much higher prevalence — an incidence of 1 in 8,000 births in Finland was reported ${ }^{27}$. Boys and girls seem to be equally affected by ARPKD. Of note, among children with PKD in paediatric nephrology departments, the total number of patients with early-onset ADPKD might be comparable to the number of children with ARPKD ${ }^{28}$. The overall prevalence of PKD in children is estimated to be $\sim 1$ in 10,000.

After delivery, the pulmonary status of neonatal infants usually dictates a requirement for early disease management of ARPKD. Mortality of 30-40\% due to pulmonary hypoplasia has been reported for ARPKD 29,30 . However, for infants who survive the perinatal period, the long-term prognosis for patient survival is much better than generally perceived by many medical professionals. One-year and 10-year survival are $\sim 85 \%$ and $\sim 82 \%$, respectively ${ }^{29-32}$.

\section{Mechanisms/pathophysiology}

The polycystin proteins are localized predominantly, although not exclusively, in the primary cilium, which is a hair-like structure that protrudes from the apical membrane of renal epithelial cells into the lumen of the nephron. The distribution of the polycystin proteins at different subcellular locations is required for them to orchestrate a network of signalling pathways that establish and maintain a differentiated renal epithelium ${ }^{33}$.

\section{ADPKD}

Genes and proteins.-Mutations in PKD1 (chromo-some 16p13.3) are responsible for almost $80 \%$ of cases of ADPKD, whereas $\sim 15 \%$ of ADPKD cases are attributed to mutations in PKD2 (chromosome 4q22.1) and the remaining 5-10\% of ADPKD cases are genetically unresolved or are due to rare mutations in other loci ${ }^{18}$. These rare mutations that 
result in an ADPKD-like phenotype occur in hepatocyte nuclear factor $1 \beta$ ( $H N F 1 B$; which is a transcription factor that upregulates the expression of multiple PKD-associated genes, including $P K H D 1$ and $P K D 2$ ), neutral a-glucosidase $\mathrm{AB}$ (GANAB; which is involved in protein folding) 34,35 and $D N A J B 11$ (which encodes a chaperone protein that is associated with binding-immunoglobulin protein (BiP; also known as HSPA5)) ${ }^{36}$. In addition, ADPKD can result from mutations in genes that are primarily associated with autosomal dominant polycystic liver disease (ADPLD), including SEC63 (which encodes a protein that is required for protein translocation across the endoplasmic reticulum (ER) membrane) and $P R K C S H$ (which encodes the regulatory $\beta$-subunit of glycosidase 2 that is involved in protein folding $)^{37-39}$. Patients with mutations in $G A N A B$ can manifest with an ADPKD or ADPLD phenotype, and other possible ADPLD-causing genes include LRP5 (which encodes a WNT co-receptor), $A L G 8$ (which encodes an a-1,3-glucosyltransferase) and $S E C 61 B$ (which encodes the $\beta$-subunit of the SEC61 trans-locon) ${ }^{35,40}$. Carriers with a mutation in one PKHD1 allele may also sometimes manifest with a few liver or kidney cysts $^{35,41}$. In addition, autosomal dominant tubulointer-stitial kidney disease (ADTKD) caused by mutations in uromodulin (UMOD), mucin 1 (MUC1), renin (REN) and SEC61A (which encodes the a-subunit of the SEC61 translocon) can also sometimes be mistaken for ADPKD, although ADTKD is usually associated with renal impairment without renal enlargement and with only a few cysts ${ }^{42-45}$. Mutations in COL4A1 (which encodes a collagen subunit), including those associated with hereditary angiopathy with nephropathy, aneurysms and muscle cramps (HANAC) syndrome ${ }^{46}$, can sometimes cause an ADPKD-like phenotype ${ }^{18}$. The X-linked ciliopathy caused by mutations in OFD1 (which encodes a centriole and centriolar satellite protein and is associated with oral-facial-digital syndrome type I) can also sometimes be confused with ADPKD, although additional facial and digital phenotypes are usually present. In summary, mutations in PKD1 and PKD2 are the main cause of ADPKD, but mutations that interfere with the biogenesis of PC1, reduce the expression of $P K D 1$ or $P K D 2$ or ciliopathy and other mutations can sometimes mimic $\mathrm{ADPKD}^{18}$. ADPKD can sometimes also be mimicked by the hereditary cancer syndromes tuberous sclerosis and von Hippel-Lindau syndrome in cases in which extrarenal features are either absent or mild ${ }^{47}$.

PC1 is a large, integral membrane protein of 4,303 amino acids with 11 transmembrane domains, an extensive extracellular domain containing multiple predicted motifs and a small, 200-amino acid intracellular carboxy-terminal tail that regulates multiple signalling cascades $^{48}$ (FIG. 2). PC1 is cleaved at the G protein-coupled receptor proteolytic site to generate a large amino-terminal fragment that remains non-covalently tethered to the carboxy-terminal fragment at the plasma membrane ${ }^{49}$. This cleavage seems to regulate the biogenesis and trafficking of PC1 (REF. $\left.{ }^{50}\right)$. In addition, regulated cleavage of the intracellular C-terminal tail releases PC1 fragments into the cytoplasm, which translocate to the nucleus and interact with transcription activators, repressors and co-activators to modulate various signalling pathways ${ }^{51,52}$.

Although many of the functions of PC1 remain unclear, the C-terminal tail of PC1 is known to mediate the interaction of PC1 with PC2 (REF. ${ }^{53}$ ), which is involved in the regulation of ion transport and indirectly affects $\mathrm{Ca}^{2+}$ signalling. The cryo-electron microscopy structure 
of PC2 establishes it as a homotetrameric ion channel, although it is possible that PC2 heteromultimerizes with other TRP channel subunits or with PC1 (REFS $\left.{ }^{54,55}\right)$.

Patients with ADPKD usually carry a germline mutation in one allele of either PKD1 or $P K D 2$ (see Diagnosis section, below), although at least one second event, such as somatic inactivation of the remaining wild-type $P K D 1$ or $P K D 2$ allele or loss of heterozygosity, is required to initiate cyst formation ${ }^{56-58}$. In addition, variants in other genes linked to $\mathrm{PKD}^{59}$ or unidentified modifying genes, as well as environmental factors such as acute kidney injury, can modulate cyst formation and disease progression ${ }^{60,61}$. The likelihood of cyst formation substantially increases when the level of functional PC1 or PC2 drops below a critical threshold ${ }^{56-58,62,63}$; accordingly, the amount of functional PC1 or PC2 and, thereby, the type of mutation (for example, inactivating mutations or mutations that reduce the function of the gene product (hypomorphic mutations)) affect the likelihood of cyst formation and the disease progression ${ }^{62-64}$ (FIG. 3). In mice, disruption of $P k d 1$ in a small number $(10 \%)$ of cells leads to an $\sim 6$-month dormant period in which there is no renal tubular dilatation, followed by a period with rapid cyst formation, suggesting that additional triggers are required to initiate cyst formation ${ }^{60,65}$.

Determinants of disease severity.-The renal phenotype in patients with ADPKD ranges from patients in old age without renal failure to rare cases of enlarged kidneys that are detected in utero ${ }^{18}$. The identity of the gene that is mutated in patients with ADPKD explains part of this phenotypic variability, so that patients with a mutation in PKD1 have earlier-onset ESRD, lower glomerular filtration rate (GFR) and larger kidney volumes than patients with a mutation in $P K D 2$ (REFS ${ }^{64,66}$ ). Sex is increasingly recognized as important to the outcome of renal disease in patients with ADPKD - in general, renal disease is substantially more severe in men than in women ${ }^{66,67}$. However, $>80 \%$ of patients with ADPKD and severe polycystic liver disease (PLD) are female, suggesting that hormonal differences might influence disease severity ${ }^{68}$. The role of $P K D 1$ allelic effects is becoming clearer, as a considerable proportion of in-frame $P K D 1$ mutations are incompletely penetrant (hypomorphic) and result in ESRD later in life, lower GFR and smaller kidneys than with more penetrant alleles ${ }^{64,66}$. However, genic or allelic effects do not seem to be important for the development of severe PLD in patients with ADPKD ${ }^{68}$.

Mutational inactivation of both alleles of $P K D 1$ or $P K D 2$ is thought to cause embryonic lethality in humans (as in mice); however, patients with biallelic mutations who are homozygous or compound heterozygous, with at least one weak PKD1 or PKD2 hypomorphic allele (that is, with a reduced level of activity or expression), do survive ${ }^{63}$. Biallelic mutations cause rare severe cases of onset of ADPKD in utero ${ }^{59,69-72}$. A mouse model mimicking the hypomorphic $P K D 1^{\mathrm{R} 3277 \mathrm{C}}$ allele shows the association of the dosage of functional PC1 to disease severity ${ }^{63}$. Digenic patients with ADPKD (that is, those with mutations in both $P K D 1$ and $P K D 2$ ) have more severe disease than monogenic family members, but digenic mutations are not lethal in humans ${ }^{73}$. The combination of an ADPKD allele with an allele of another cystogene, such as $H N F 1 B$, may also exacerbate the renal disease phenotype ${ }^{59}$. 
At least $10-15 \%$ of families with ADPKD have no family history of the disease, suggesting that de novo mutations occur at a considerable rate, and intrafamilial variability in this case can be explained by mosaicism, in which the proportion of cells that carry the mutation and those that contain the wild-type allele can differ substantially ${ }^{74,75}$. Mosaicism can be more reliably detected by next-generation sequencing (NGS)-based approaches than by conventional sequencing owing mainly to the superior sequencing depth in $\mathrm{NGS}^{47}$.

Finally, studies of twins and those that analysed inter-familial and intrafamilial variability in ADPKD severity suggest that other genetic factors contribute substantially to the variability in the severity of renal disease ${ }^{66,76-78}$, although, to date, the identity of these other genetic factors is unknown ${ }^{79}$.

Arterial hypertension.-Early in the course of ADPKD when renal function is still normal, most patients already develop arterial hypertension that contributes considerably to the increased cardiovascular morbidity and mortality observed in patients with ADPKD. Although various pathogenic mechanisms are known and activation of the reninangiotensin-aldosterone system (RAAS; a hormone system that regulates blood pressure and fluid balance) is clearly the most prominent, other mechanisms have also been described, including increased activity of the sympathetic nervous system and disturbances in the fine-tuning of vascular tone through the action of endothelin, nitric oxide (NO) and intracellular calcium (reviewed elsewhere ${ }^{33}$ ).

Cyst formation.-The cysts in patients with ADPKD are fluid-filled focal outgrowths from the renal epithelium, which arise in a minority $(\sim 1 \%)$ of nephrons and eventually detach when the amount of functional PC1 or PC2 drops below a critical threshold level. The polycystin proteins localize to the apical and basolateral plasma membrane, adherens junctions, desmosomes, focal adhesions and the primary cilium and are also secreted in microvesicles ${ }^{80}$. In addition, PC2 is localized to the ER and mediates $\mathrm{Ca}^{2+}$ release from this organelle. The polycystin proteins form multimeric protein complexes that modulate several signalling pathways, such as $\mathrm{Ca}^{2+}$, cAMP, mechanistic target of rapamycin (mTOR), WNT, vascular endothelial growth factor (VEGF) and Hippo signalling. Consequently, numerous cellular changes have been observed in cyst-lining cells, including alterations in apical-basal polarity, planar cell polarity (PCP), increased extracellular matrix production and cellular metabolism, involving essential cellular functions such as fluid transport, proliferation, apoptosis, cell adhesion and differentiation ${ }^{81-85}$ (FIG. 4).

However, as PKD progresses, the molecular alterations in the kidneys are increasingly the consequence of secondary events that disrupt the network of signalling pathways. Reduced $\mathrm{Ca}^{2+}$ influx, increased cAMP levels and aberrant RAS-RAF-ERK activation in renal epithelial cells are important mediators of cyst growth. which is further sustained by increased growth factor signalling ${ }^{86,87}$. For example, increased levels of epidermal growth factor receptor (EGFR) and its mislocalization to the apical surface of cystic epithelial cells, together with the presence of the ligands EGF and transforming growth factor-a (TGFa) in cyst fluid, probably promote tubular epithelial cell proliferation ${ }^{88,89}$. Other mechanisms that might be involved in cyst growth include altered signalling through G proteins, mTOR, phosphoinositide 3-kinase (PI3K)-AKT, AMP-activated protein kinase (AMPK), Janus 
kinase 2 (JAK2)-signal transducer and activator of transcription 1 (STAT1; or STAT3 or STAT6), nuclear factor of activated T cells (NFAT) and nuclear factor- $\mathrm{KB}$ (NF-KB) ${ }^{90-97}$. In addition, cyst expansion is accompanied by changes in cellular metabolism - increased glucose consumption that is indicative of ATP synthesis through aerobic glycolysis, and impaired fatty acid oxidation, seem to be additional features of ADPKD ${ }^{83,98-102}$. Cysts can induce stress (presumably mechanical) on neighbouring nephrons, resulting in apoptosis of renal epithelial cells and thereby locally increasing the likelihood of cyst formation ${ }^{65}$.

The polycystin complex localized in the primary cilium was initially thought to transduce extracellular fluid flow-generated shear stress into a cellular $\mathrm{Ca}^{2+}$ signal ${ }^{86}$, but subsequent studies suggested that although polycystin proteins induce local changes in ciliary calcium concentration through their channel function, global cytoplasmic calcium levels are not substantially altered ${ }^{87}$. Intriguingly, the engineered loss of cilia ameliorates the cystic phenotype in $P k d 1$-mutant mice or $P k d 2$-mutant mice, suggesting that, in healthy kidneys, the polycystin proteins inhibit a cilia-regulated cystogenic signalling pathway that controls renal epithelial cell proliferation ${ }^{103}$.

However, the function of the polycystin proteins at other subcellular locations should not be underestimated. Simultaneous ablation of $P k d 1$ and $\operatorname{Itgbl}$ (which encodes $\beta 1$ integrin) in mice resulted in inhibition of $P k d 1$ ablation-dependent cystogenesis and suppression of fibrosis, suggesting that $\mathrm{PC} 1$ represses signalling that regulates the crosstalk between the extracellular matrix and integrins ${ }^{104}$. Although a direct association between PC1 and $\beta 1$ integrin has not been detected, $\mathrm{PC} 1$ interacts with the cytoskeletal adaptor proteins vinculin and paxillin, which are essential for integrin signalling through focal adhesion complex proteins, such as focal adhesion kinase (FAK) and $\mathrm{SRC}^{105}$. The accumulation of the extracellular matrix and the recruitment of inflammatory cells can already be observed at early stages of the disease. In particular, M1 and M2 macrophages are important contributors to disease progression. Macrophages and interstitial fibroblasts also produce cytokines, and abnormal cytokine-mediated crosstalk between renal epithelial cells and inflammatory cells results in a positive feedback loop of increasing fibrosis (FIG. 5).

In addition to altered cell-matrix interactions, the cell-cell junctions in cyst-lining epithelia are also abnormal ${ }^{106}$. The abnormal composition and localization of adherens junctions and desmosomes in ADPKD suggest that the polycystin proteins regulate the dynamics of cellcell adhesions to reduce their mechanical strength and allow cytoskeletal remodelling in $\mathrm{ADPKD}^{106,107 .}$

As a consequence, the integrity of apical-basal polarity and PCP is compromised in cystic epithelial cells ${ }^{108}$. However, although disruption of PCP signalling results in inaccurate control of tubule diameter, it is not cystogenic ${ }^{109}$. These data suggest that $P K D$ mutations do not disrupt PCP signalling but instead act independently of and in parallel with PCP signalling to affect oriented epithelial cell division ${ }^{107}$.

Overall, cystic epithelia often have a partially de-differentiated phenotype, suggesting that mutations in the PKD genes result in cells reverting to a developmental pattern of gene expression. Although the molecular mechanisms of polycystin regulation of various 
signalling pathways at different subcellular locations are not fully understood, this network of signalling pathways seems to be crucial for establishing and maintaining a differentiated renal epithelium ${ }^{60}$.

Histopathological changes.-Epithelial cell proliferation, abnormal fluid secretion and excessive extracellular matrix deposition are the major characteristics of cystic epithelial cells. These changes are accompanied by alterations in the pericystic blood and lymphatic microvas-culature ${ }^{110-112}$. Most cysts detach from the tubules from which they form and fill with fluid by transepithelial secretion ${ }^{113}$. Cyst enlargement also compresses the surrounding nephrons, interstitium and vasculature. The obstructed nephrons eventually form atubular glomeruli and apoptotic proximal tubules ${ }^{114}$.

These events are accompanied by the production of chemokines, cytokines and growth factors by epithelial cells, interstitial fibroblasts and inflammatory cells, such as macrophages ${ }^{115,116}$. Abnormal cytokine-mediated crosstalk between epithelial and inflammatory cells promotes more inflammation and fibrosis, new cyst formation and disease progression, which result in massively fibrotic kidneys at end-stage disease ${ }^{117}$ (FIG. 5). Increased inflammation is probably an early event in disease progression, and the selective depletion of macrophages in the kidneys of a $P k d 1$ mouse model resulted in considerable amelioration of the cystic phenotype and improvement in renal function ${ }^{118}$. Macrophage migration inhibitory factor (MIF) is an important pro-inflammatory cytokine in PKD, as deletion of Mif delayed cyst growth and improved renal function in Pkd1-knockout mice $^{119}$.

Extrarenal pathology.-ADPKD is a systemic disease and, in addition to the renal pathology, patients develop liver cysts and cardiovascular abnormalities. PLD is characterized by the presence of multiple cysts scattered throughout the liver parenchyma, which form owing to overgrowth of the biliary epithelium. The severity of PLD can range from a few hepatic cysts to a massively enlarged cystic liver. As in renal epithelia, a substantial reduction or complete loss of function of the polycystin proteins underlies liver cyst formation ${ }^{120}$. PLD can also occur as a distinct disease, without the involvement of renal cysts, as ADPLD. Although ADPLD is caused by mutations in a set of genes that are distinct from those involved in ADPKD, studies in mice suggest that mutations in these PLD genes affect the dosage of PC1, which seems to be the rate-limiting determinant of liver cyst formation $^{121}$.

Patients with ADPKD also have cardiovascular abnormalities, including hypertension, left ventricular hypertrophy, aortic root dilatation, arterial aneurysms, heart valve abnormalities and intracranial aneurysms (ICAs) (reviewed elsewhere ${ }^{122}$ ). Numerous lines of evidence suggest that the vascular and cardiovascular defects are directly related to reduced expression of the polycystin proteins (haploinsufficiency) in the endothelial cells and vascular smooth muscle cells (VSMCs) of most blood vessels, including the aorta and cerebral arteries ${ }^{110,114}$. Indeed, the risk of cerebral aneurysms is higher in families with a positive family history of ADPKD than those without, probably because of modifying genes $^{123}$. The functions of PC1 and PC2 in the vasculature indicate that they have a crucial role in mechanosensation. In endothelial cells, the proteins are involved in fluid-shear stress 
sensing, thereby regulating calcium signalling and NO release ${ }^{124}$. NO released by endothelial cells affects vasodilatation in response to increased blood flow. In VSMCs, the polycystins regulate pressure sensing by modulating the activity of the stretch-activated cation channels and myogenic contraction ${ }^{125}$. A loss of myogenic tone may contribute to aneurysm formation owing to an increase in arterial wall stress ${ }^{125}$. Finally, studies of haploinsufficient and hypomorphic models of ADPKD have shown that vascular changes are associated with a reduction of the levels of polycystin proteins ${ }^{126-128}$.

The $P K D$ genes are expressed in a wide range of tissues beyond the kidney, and their expression is developmentally regulated in most of these tissues. Accordingly, other extrarenal manifestations can occur, including cysts in the pancreas, seminal vesicles and the arachnoid membrane, in patients with ADPKD ${ }^{115}$. Although patients with a single or those with more than one mutant $P K D$ allele usually have relatively restricted disease phenotypes (that is, cysts or manifestations in only a few organs), complete knockout of $P k d 1$ or $P k d 2$ in mice results in embryonic lethality that is associated with a wide range of abnormalities, including: severely cystic pancreas, kidneys and liver; cardiac abnormalities; vascular defects (such as oedema and vascular leakage); craniofacial defects; bone defects; and, rarely, polyhydramnios (excess amniotic fluid) ${ }^{129-133}$. Tissue-specific $P k d 1$ or $P k d 2$ disruption results in hydrocephalus and lymphatic abnormalities in mice ${ }^{112,134}$. The speciesspecific differences in ADPKD phenotypic severity suggest that the levels of polycystin proteins in most human tissues do not drop below a critical threshold or that when this happens, the affected cells might undergo apoptosis.

Experimental models.-To gain insight into the disease mechanisms and pathogenesis of ADPKD, various mouse models have been genetically engineered ${ }^{33}$, including inducible, conditional knockout mice and mouse models with hypomorphic or hypermutable alleles of $P k d 1$ or $P k d 2$, which are extremely useful as ablation of $P k d 1$ or $P k d 2$ results in embryonic lethality and heterozygous mice develop only very mild disease, even in old age ${ }^{62,63,135-139}$. These models are characterized by the age of disease onset, the progressiveness of the disease, the nephron segment that is affected, the number of affected nephrons, whether cyst formation is synchronized or unsynchronized and the extent of renal fibrosis and inflammation. These models enable step-by-step analysis of the pathogenesis of ADPKD and have provided valuable mechanistic insights into the early stages and the later, progressive stages of the disease. Findings in tissues from mouse models of early disease are complementary to those in renal tissues from patients with ADPKD, as the kidneys are usually removed from patients with the progressive stages of ADPKD or ESRD. Examples of the value of animal models include their role in highlighting the difference in the severity of renal disease observed when $P k d 1$ is inactivated during renal development compared with after the kidneys have formed ${ }^{137,138}$. In addition, renal damage was shown to increase the severity of PKD in haploinsufficient mice ${ }^{60,140}$. Finally, hypomorphic models have shown that polycystic kidneys can develop when polycystin function is reduced but not eliminated ${ }^{62,63}$. 


\section{ARPKD}

Genes and proteins.-The polycystic kidneys and congenital hepatic fibrosis (CHF) observed in ARPKD suggest that terminal differentiation of the renal collecting ducts and intrahepatic biliary ducts is disordered in this disease. Histological analysis has revealed that the changes in the liver that are invariably present from early embryonic development in patients with ARPKD are characterized by defective remodelling of the ductal plate with CHF and biliary duct ectasia, defined as ductal plate malformation (DPM; FIG. 6), which also occurs frequently in other cilia-related disorders (ciliopathies), such as nephronophthisis, Joubert syndrome and Bardet-Biedl syndrome, some ofwhich may have an ARPKD-like phenotype ${ }^{1,141}$. Different types of variants in PKHD1 (6p12.3-12.2), such as missense and truncating mutations, are responsible for most cases of ARPKD (discussed further in the Diagnosis section).

The mRNA of $P K H D 1$ is alternatively spliced to produce multiple transcripts ${ }^{142,143}$. The longest transcript encodes a 4,074-residue protein comprising a single transmembrane domain, an extensive extracellular $\mathrm{N}$-terminal domain and a short $\mathrm{C}$-terminal cytoplasmic tail (FIG. 2). Fibrocystin localizes to the primary cilium and to other cellular compartments ${ }^{142,144,145}$ and is targeted to the ciliary membrane by a specific motif in its C terminus ${ }^{146}$. In addition, similar to Notch, fibrocystin is proteolytically cleaved to release the cytoplasmic tail, which translocates to the nucleus and presumably regulates downstream target genes. Although this remains to be conclusively established, it is possible that the Cterminal tail of fibrocystin regulates the expression of genes that encode proteins that drive cyst formation ${ }^{147,148}$.

In addition, mutations in the gene encoding the ciliary transition zone protein DAZinteracting protein 1-like protein (DZIP1L) have been described in some pedigrees in which the affected children had clinically moderate ARPKD and no evidence of mutations in PKHD1 (REF. ${ }^{132}$; C.B., unpublished data). DZIP1L is a 767-residue soluble zinc-finger protein that, similar to PC1, PC2 and fibrocystin, localizes to centrioles and the distal end of basal bodies. DZIP1L interacts with septin 2 (SEPT2; in the septin ring), a protein that is implicated in the maintenance of the periciliary diffusion barrier at the ciliary transition zone. Consistent with a defect in the diffusion barrier, the localization of PC1 and PC2 to the ciliary membrane is compromised in DZIPIL-mutant cells ${ }^{132}$. Diseases with symptoms similar to those in ADPKD and ARPKD might also be caused by mutations in other genes (reviewed in detail elsewhere ${ }^{1}$ ). Of note, mutations in PKD1 and PKD2 can also be inherited in a recessive manner (homozygous or compound heterozygous) with at least one weak $P K D 1$ or $P K D 2$ hypomorphic allele; these patients can present with an ARPKD-like phenotype $^{141}$.

Finally, PKD (mimicking ARPKD or ADPKD) with hyperinsulinie hypoglycaemia was described in 11 pedigrees and was linked to biallelic mutations (including a specific promoter mutation) in phosphomannomutase $2(P M M 2)^{149}$. PMM2 is a key enzyme in $N$ linked glycosylation, and recessive mutations in $P M M 2$ are usually associated with congenital disorder of glycosylation type 1a, which has a severe, pleiotropic phenotype. 
Determinants of disease severity.-Efforts to assess geno-type-phenotype correlations for PKHD1-linked ARPKD have been hampered by multiple allelism (that is, the presence of many different mutations in the same gene) and the high incidence of different compound heterozygotes (that is, the presence of two different mutant alleles at a single locus).

However, genotype-phenotype correlations have been made for the type of mutation instead of the site of individual mutations ${ }^{150}$. Allelic effects are known; for example, patients with two truncating mutations in $P K H D 1$ often have severe disease that is usually lethal (although a few exceptions have been described) and surviving patients typically have at least one inframe mutation ${ }^{30,150}$. These data indicate that many missense mutations do not completely abrogate PKHD1 function. Notwithstanding, some missense mutations in PKHD1 result in disease that is as severe as that resulting from truncating mutations. No substantial clinical differences have been observed between patients with two missense mutations and patients with a truncating mutation in trans; thus, the milder mutation seems to define the disease severity. Substantial intrafamilial variability among a considerable number of siblings indicates that other genetic and environmental factors also influence the disease phenotype ${ }^{32}$.

The clinical course in patients and siblings with DZIPIL mutations described above was invariably moderate. Although the clinical manifestations in all of these patients were initially detected prenatally or during early childhood, none of the patients died perinatally. To date, the data are consistent with the idea that the type or location of the mutation in DZIPIL does not determine the severity of the clinical course. Patients who have missense mutations in both parental DZIPIL alleles have a phenotype comparable to that of patients who have two truncating DZIPIL alleles. Although genetic screening of a large number of patients who died perinatally has not been carried out, in view of homozygous truncating mutations in two patients ${ }^{132}$, we hypothesize that it is unlikely that DZIPIL mutations play a major role in this cohort of mostly severely affected patients. This hypothesis is consistent with the birth of homozygous Dzip11-mutant outbred mice at the expected Mendelian frequencies ${ }^{132}$. However, the identification of additional families with DZIPIL mutations is required to draw firm conclusions.

Cyst formation.-ARPKD cysts arise predominantly from the distal tubules and collecting ducts, but the detailed mechanisms of cyst formation are only poorly understood. Fibrocystin is expressed postnatally predominantly in the kidneys, liver and pancreas, and as mentioned earlier, fibrocystin localizes to the apical membranes as well as to primary cilia, especially at the basal body and the mitotic spindle in renal tubular cells and biliary epithelial cells ${ }^{145,151,152}$. DZIP1L is widely expressed and is localized primarily to centrioles and the distal end of basal bodies. Although little is known about the molecular functions of fibrocystin and DZIP1L, fibrocystin has been shown to interact with PC2 within the PC1-PC2 complex ${ }^{153}$. In addition, as in ADPKD, the cAMP, MYC and mTOR signalling pathways are activated in $\mathrm{ARPKD}^{154}$ and thus represent potential targets for directed therapeutic intervention.

Experimental models of ARPKD.-To date, multiple Pkhd1-based models of ARPKD have been described, which were primarily generated by gene-targeting methods in mice. 
Although an ARPKD-like liver phenotype is invariably present in all of these mouse models, a renal phenotype is often absent, and when present, it is a mild, slowly progressive lesion that typically involves the proximal tubules rather than the collecting ducts. Interestingly, several models also have a severe pancreatic ductal phenotype, whereas clinically significant pancreatic disease in patients with ARPKD is quite rare. The mechanism that underlies the mild renal phenotype in these animal models remains unclear. However, as genetic background seems to have a major effect on renal pathology, genetic modifiers likely modulate renal disease ${ }^{155}$. In the PCK rat, which arose owing to a spontaneous mutation in Pkhd1 (REF. ${ }^{144}$ ), the hepatic phenotype is very similar to that in ARPKD, whereas the slowly progressive renal cystic disease in this model more closely resembles the renal cystic lesions in ADPKD than in ARPKD ${ }^{156}$. Introgression of the Pkhd1 mutation in the PCK rat into a different background ameliorated the renal but not the hepatic phenotype, again suggesting that genetic factors modulate the severity of the renal cystic phenotype ${ }^{157}$.

Consistent with the extensive phenotypic variability observed in experimental models of ARPKD, Dzip1N ${ }^{\text {wpy/wpy }}$ mice (which were identified in an $N$-ethyl-N-nitrosourea-induced mutagenesis screen and contain a nonsense mutation in Dzip11) display a number of embryonic morphological defects, including limb and craniofacial defects, in addition to cystic kidney disease and hepatobiliary DPM ${ }^{132}$. The amelioration of the craniofacial phenotypes by crossing Dzip1/Npy/wpy mice with an outbred strain suggests that at least some of the phenotypic differences with the human ARPKD may be due to genetic background effects. Tissue-specific changes in the expression of genes involved in Hedgehog signalling, such as gene expression changes in the limb that are consistent with polydactyly, were detected in Dzip1 ${ }^{\mathrm{wpy} / \text { wpy }}$ embryos $^{132}$.

\section{Diagnosis, screening and prevention}

\section{ADPKD}

Diagnosis.-ADPKD is a progressive disease in which renal cyst development begins in utero, although cyst initiation and enlargement continue throughout the patient's life ${ }^{158}$. Cyst enlargement results in an exponential increase in total kidney volume (TKV; expressed relative to height (htTKV)) and often results in $\mathrm{ESRD}^{159}$. Clinical symptoms, including early-onset hypertension, abdominal fullness and pain, haematuria and urinary tract infections (UTIs), are usually first observed decades (sometimes even in childhood) before the onset of renal insufficiency ${ }^{2}$ (the numerous manifestations of the disease are described in TABLE 1).

Presymptomatic diagnosis can usually be made in at-risk family members (such as children or siblings of affected individuals) by abdominal imaging, and the presence of multiple bilateral cysts identifies affected individuals. Ultrasonography is the most common and least expensive imaging method, but CT or MRI can provide more quantitative data (that is, htTKV) of prognostic value (FIG. 7). As cyst development in ADPKD is related to age, and even genetically unaffected individuals can develop a few simple cysts as they age ${ }^{160}$, criteria have been developed to define whether at-risk individuals are affected on the basis of number of cysts by age (TABLE 2). 
The corresponding number of MRI-detected cysts that are considered to be diagnostic has been defined as more than ten in those aged 16-40 years; fewer than ten cysts does not classify as $\mathrm{PKD}^{161}$. In patients without an established family history, the detection of more than ten cysts per kidney by ultrasonography is usually considered diagnostic ${ }^{162}$, but genetic diagnostic testing would be valuable.

Imaging provides a less certain diagnosis in young adults owing to the late and only mild disease manifestation in some patients; therefore, in these cases and others, genetic analysis may be helpful to obtain a definite diagnosis (BOX 1).

Obtaining a genetic diagnosis of ADPKD is complex because of historical segmental intrachromosomal duplication of three-quarters of the $P K D 1$ gene (at the $5^{\prime}$ end), which produced six pseudogenes that have up to $99 \%$ sequence homology with PKD1.

Consequently, specialized screening of $P K D 1$ is required because mutations are not always detected by whole-exome sequencing (WES). Traditionally, genetic diagnostic analysis has involved using $P K D 1$-specific long-range PCR fragments that exploit the rare sequence differences between $P K D 1$ and the pseudogenes, followed by Sanger sequencing or NGS of the long-range products to identify mutations ${ }^{163-165}$. However, newer sophisticated NGS methods that use specific capture workflows and in silico analyses ${ }^{166,167}$ or whole-genome sequencing (WGS) ${ }^{168}$ have been reported, and capture-panel-based approaches are now favoured for genetic diagnosis of ADPKD.

Furthermore, interpretation of the results of genetic diagnostic analysis is complicated not only by the $P K D 1$ pseudogenes but also by the high level of allelic heterogeneity in PKD1 and $P K D 2$, in which $>1,900$ different mutations have been described, and no single mutation accounts for $>2 \%$ of the total patient population (ADPKD Mutation Database). A substantial proportion of $P K D 1$ mutations are in-frame $(\sim 30 \%)$, and because this gene has $>300$ described neutral non-synonymous variants, determining whether a missense variant is pathogenic is not always straightforward. Inquiry of the ADPKD Mutation Database and the use of scoring algorithms together with contextual information from population databases (for example, the Genome Aggregation Database (gnomAD) and family studies can help determine the pathogenicity of these variants $66,163,169,170$. In 7\% of ADPKD families, no mutation is detected ${ }^{64,66,163,164}$; some of these families probably have mutations at the known PKD loci that were not detected (for example, deep intronic or regulatory mutations), including mosaic cases that are probably more common in patients with de novo mutations than is currently reported ${ }^{75,171,172}$. In addition, further genetic heterogeneity is likely, as mutations in GANAB were identified as a cause of mild ADPKD, which represents $\sim 0.3 \%$ of all cases ${ }^{34}$, and $D N A J B 11$ mutations cause a hybrid of ADPKD and ADTKD ${ }^{36}$. Phenocopies of the ADPKD phenotype can also be due to mutations in $H N F 1 B$ and in other genes, such as those associated with ADPLD that result in an ADPKD-like phenotype ${ }^{173,174}$. Parental renal ultrasonography should be carried out for family members of children who have cystic kidney disease of unknown origin. However, the family history is often unremarkable because of de novo mutations and combinations of incompletely penetrant (hypomorphic) alleles. 
Asymptomatic at-risk individuals $<18$ years of age are usually not screened but decide whether and when to be tested as an adult ${ }^{31,175}$. The rationale for this recommendation is based on the current lack of disease-specific treatments for those individuals $<18$ years of age and, in the USA at least, problems can occur with obtaining medical insurance and with workplace issues, despite antidiscrimination legislation. When necessary, monitoring and treatment of arterial hypertension and UTIs in at-risk children are recommended. However, the recommended age of testing may change if therapies become available for those $<18$ years of age after the completion of clinical trials in children and teenagers. Treatment of young individuals (even children) before irreparable kidney damage has occurred might be particularly effective. Increasing evidence exists that important predictors of future cardiovascular events and mortality (such as left ventricular hypertrophy, biventricular diastolic dysfunction, endothelial dysfunction, increased carotid intima-media thickness and impaired coronary flow velocity reserve) are evident in children and young individuals with normotensive blood pressure and normal kidney function very early in the disease course and that patients might benefit from an early diagnosis $75,176,177$.

Prognosis.-Identifying patients with rapidly progressing disease would facilitate selection for clinical trials and treatment. Separating patients into classes on the basis of agerelated htTKV (the Mayo Classification), and exclusion of atypical patients, have been proposed as an efficient means to identify patients with the most rapidly progressing disease $^{178}$. Combining genic and allelic information with clinical indications (onset of hypertension at $<35$ years of age and/or first urological event at $<35$ years of age) has also enabled identification of a population with rapidly progressing disease (the PROPKD score, a prognostic algorithm to predict renal outcomes in patients with ADPKD on the basis of genetic and clinical data) ${ }^{67,179}$. European recommendations have highlighted a demonstrated rapid decline in GFR in younger patients and/or a recorded rapid increase in htTKV as a means to identify patients with rapidly progressing disease who are suitable for treatment ${ }^{179}$.

Prenatal screening.-As ADPKD is an adult-onset disease, prenatal screening is not commonly carried out, but there is increasing interest in this procedure, especially from families with experience of early-onset renal disease or early ICAs. Of note, affected families with children with early-onset ADPKD have a high risk of subsequent children also having early and severe ADPKD, and this information should be shared with affected families ${ }^{1}$. Preimplantation genetic diagnosis is available for ADPKD, including analysis of the duplicated PKD1 locus, and may be more commonly sought in the future ${ }^{44}$.

\section{ARPKD}

Diagnosis.-ARPKD is phenotypically highly variable: at its most severe, ARPKD presents in utero, at birth or in infancy and is characterized by bilaterally enlarged, echogenic kidneys with poor corticomedullary differentiation, retained reniform contour and multiple tiny cysts that are confined to the distal tubules and collecting ducts (FIG. 8); presentation in older children, teenagers or young adults includes manifestations of portal hypertension or cholangitis; and moderate presentation is seen rarely in older adults with complications of liver disease or with renal manifestations, such as proteinuria, nephrolithiasis and renal insufficiency ${ }^{180-183}$. Those patients who survive the perinatal 
period then transition from paediatric to adult care with internal medicine specialists ${ }^{184}$. With the advent of NGS-based molecular diagnostic testing, it has become evident that mutations in various other genes, such as $H N F 1 B$ and those associated with ADPKD and many ciliopathies, can produce a phenotype that mimics the symptoms in ARPKD ${ }^{141}$.

Potter sequence consists of pulmonary hypoplasia, characteristic facies and spine and limb abnormalities and can be present in severe neonatal cases, with death from respiratory distress occurring in at least $20 \%$ of cases ${ }^{26,30,32}$. Surviving infants can experience childhood ESRD as well as liver complications owing to CHF that worsens with age. Patients who present with ARPKD later in childhood or as adults are more likely to have complications of portal hypertension, whereas renal enlargement is less evident than in patients who present earlier ${ }^{32,181}$. With advancing clinical course, the kidney structure might increasingly resemble the symptoms observed in ADPKD, including renal cysts that vary considerably in size and appearance, often accompanied by some interstitial fibrosis ${ }^{185}$. However, in contrast to the persistent renal enlargement that occurs in ADPKD, in ARPKD the kidneys decrease in size as the amount of fibrosis increases.

A diagnosis of ARPKD is likely to be based on clinical imaging in severe neonatal or infantile cases on the basis of enlarged echogenic kidneys, a negative family history of PKD and a lack of additional features (such as central nervous system abnormalities, eye defects and/or polydactyly) that may suggest a syndromic ciliopathy ${ }^{1}$. However, molecular diagnostic analysis is the gold standard for diagnosing this disorder, and a number of phenocopying disorders or syndromes must be considered ${ }^{1}$. Genetic testing can be particularly important in the diagnostic evaluation of patients with early-onset bilateral renal cystic disease. In older patients, CHF with or even without renal cysts may indicate ARPKD and molecular diagnostic analysis may help confirm the diagnosis ${ }^{47}$.

The large size of the $P K H D 1$ gene (12,222 bp coding sequence, 67 exons and spans $\sim 470$ $\mathrm{kb})^{142,144}$ and a high level of allelic heterogeneity ( $60 \%$ of mutations are inframe and $40 \%$ of mutations are truncating ${ }^{150,186}$ ) complicate the molecular diagnosis of ARPKD. Some mutations in PKHD1 are more common than others and some are enriched in specific populations; for example, T36M is the most common mutation and accounts for $\sim 10-15 \%$ of mutant alleles in European populations ${ }^{150,186,187}$. Analysis of DZIP1L is much easier than for $P K H D 1$, as it has a 2,301 bp coding sequence, 16 exons and spans only $\sim 53 \mathrm{~kb}$.

Mutations in DZIP1L are a considerably rarer cause of ARPKD than PKHD1 mutations ${ }^{132}$, perhaps in part owing to the larger size of PKHD1 compared with DZIP1L. Furthermore, limited data suggest that the genomic region encoding the $\mathrm{N}$ terminus of DZIP1L may be more susceptible to mutations, which is supported by in silico data that predict that pathogenicity scores decay towards the $\mathrm{C}$ terminus ${ }^{132}$.

In practice, and reflecting the phenotypic overlap of ARPKD with syndromic ciliopathies as well as other forms of PKD, including ADPKD, screening a panel of genes is now often considered to be the gold standard for diagnostics ${ }^{147,167}$. Advances in NGS now enable simultaneous analysis of a large group of genes in a single test at fairly low cost. We expect that single-gene testing will soon be the exception rather than the rule, especially for genetically heterogeneous disorders with a broad phenotypic spectrum such as PKD. 
However, at present, targeted NGS panel testing might be the most efficient diagnostic approach. Whichever primary strategy is chosen for PKD diagnosis, it should be able to detect copy number variations such as heterozygous deletions (for example, in $H N F 1 B$ ) and to cover complex genomic regions, such as $P K D 1$.

Prognosis.-In accordance with autosomal recessive inheritance, the recurrence risk for subsequent pregnancies of parents of an affected child with ARPKD is 25\%. Males and females are equally affected ${ }^{30}$. By definition, heterozygous carriers should not show any clinical disease manifestation, but data suggest that individuals who are heterozygous for PKHD1 mutations have an increased risk of PLD and mild PKD ${ }^{35,41}$. Other relatives (such as healthy siblings) or the affected patients themselves may seek genetic counselling and can usually be reassured of a very low risk $(<1 \%)$ for ARPKD for their own offspring if their partner is not affected by ARPKD and has no family history of PKD.

Prenatal screening.-Many parents of children with ARPKD seek early and reliable prenatal diagnosis of subsequent children to guide future family planning. Frequently, patients with ARPKD are diagnosed by ultrasonography only late in pregnancy or at birth. However, fetal sonography at the time when pregnancies are usually terminated may fail to detect enlargement and increased echogenicity of the kidneys or oligohydramnios (deficiency of amniotic fluid) secondary to poor fetal urine output. Thus, an early and reliable prenatal diagnosis of ARPKD in at-risk families is feasible only by molecular genetic analysis. Prenatal diagnosis should be offered only to families for which there is an unequivocal diagnosis in an affected family member. However, prenatal molecular genetic analysis is usually done using chorionic villus sampling, which is an invasive procedure that is carried out quite late in pregnancy (no earlier than week 10-12 of gestation). Interested families should also be informed about the possibility of preimplantation genetic diagnosis with in vitro fertilization at some diagnostic centres. Preimplantation genetic diagnosis always requires a high degree of coordination between different medical specialists and a health assessment in advance. In the future, it might be possible to conduct non-invasive prenatal testing of the fetal genotype by screening a maternal blood sample ${ }^{188}$.

When considering prenatal testing, medical and ethical implications require a careful review by attending physicians and the parents. These tests should be embedded in an ethical framework based on the principles of beneficence and respect for autonomy. Beneficencebased clinical judgements should be evidence-based (that is, they should be based on the best available evidence), and clinical strategies should be identified that are reliably expected to result in the greatest balance of benefits (that is, the protection and promotion of healthrelated interests) over clinical harms (that is, impairments of those interests) ${ }^{189}$. Respect for autonomy and the patient's perspective is another key issue in the context of perinatal genetic testing. The physician is obliged to respect the parents' values and beliefs, to respect their perspective on their interests and to implement only those clinical strategies that are authorized as a result of informed consent ${ }^{30,189}$. 


\section{Management ADPKD}

ADPKD is a systemic disorder with renal manifestations and an increasing number of extrarenal manifestations (TABLE 1). Management of ADPKD was the subject of a report of a Kidney Disease: Improving Global Outcomes (KDIGO) Controversies Conference ${ }^{44}$, Spanish and Kidney Health Australia-Caring for Australasians with Kidney Impairment (KHA-CARI) management guidelines and a Core Curriculum ${ }^{190}$. Additionally, a classification of ADPKD disease severity into different classes (1A-1E) was developed on the basis of htTKV (which provides an accurate estimate of kidney cyst burden in ADPKD) and age ${ }^{178}$. The classification stratifies patients on the basis of the rate of GFR decline and is useful in clinical trials to identify patients with rapid disease progression who might benefit most from therapy, as opposed to patients whose disease progresses slowly and who might not need therapy ${ }^{191}$.

Lifestyle interventions to enhance hydration, limit dietary sodium and protein intake and maintain a healthy weight, as well as early detection and rigorous treatment of hypertension and possibly dyslipidaemia, might have a beneficial effect on the course of the disease. Patients with ADPKD often have a mild urinary concentration defect that usually goes undetected, which is consistent with the inappropriate antidiuresis that is observed in Pkd1 heterozygous mice ${ }^{192}$. Plasma vasopressin and its precursor copeptin, which serves as a marker of vasopressin, may be increased in patients with ADPKD, and plasma copeptin levels correlate with the severity of ADPKD in cross-sectional studies and with the rate of disease progression in prospective studies ${ }^{193}$. Increasing evidence has shown that the action of vasopressin on the kidneys may contribute not only to the progression of ADPKD but also to the progression of CKD in general ${ }^{194}$. Additionally, two large studies on cyst and kidney growth (the CRISP study) and hypertension (the HALT study) in ADPKD have shown an association between dietary salt intake and the rate of progression of ADPKD ${ }^{195}$. The CRISP and the Modification of Diet in Renal Disease (MDRD) studies suggested an association between low levels of high-density lipoprotein (HDL) cholesterol and faster rates of kidney growth or GFR decline, respectively, in patients with ADPKD ${ }^{195}$. Experimental studies have shown that moderate food or caloric restriction substantially inhibits disease progression in orthologous mouse models of ADPKD, and high body mass index in patients with ADPKD is associated with a poor outcome ${ }^{196}$.

Treatments that directly target cystogenic mechanisms (such as decreasing cAMP levels in cystic tissues) are now available. For example, the Tolvaptan Efficacy and Safety in Management of Autosomal Dominant Polycystic Kidney Disease and its Outcomes (TEMPO) 3:4 clinical trial showed that the vasopressin receptor 2 antagonist tolvaptan slowed the rate of kidney growth and estimated GFR (eGFR) decline in patients with early ADPKD (age 18-50 years, estimated creatinine clearance $260 \mathrm{ml} \mathrm{min}^{-1}$ ) ${ }^{197}$; tolvaptan has received regulatory approval in Japan, Canada, the European Union, Switzerland and South Korea for the treatment of ADPKD in patients with rapidly progressive disease. In the USA, approval from the US FDA was deferred until further data are available on the potential benefits and risks of tolvaptan treatment. The Replicating Evidence of Preserved Renal 
Function: an Investigation of Tolvaptan Safety and Efficacy in ADPKD (REPRISE) clinical trial showed that tolvaptan also slows the eGFR decline in later-stage ADPKD (age 18-65 years, eGFR $\left.25-65 \mathrm{ml} / \mathrm{min} / 1.73 \mathrm{~m}^{2}\right)^{198}$, and the FDA has now approved the therapy in the USA. In both the TEMPO 3:4 and REPRISE trials, clinically significant elevation of serum transaminases was detected in $\sim 5 \%$ of patients who were treated with tolvaptan; therefore, strict instructions to regularly monitor liver enzymes are incorporated into the treatment regimen. Potential benefits and adverse effects of tolvaptan treatment should be considered before prescribing tolvaptan, and the treatment is also recommended only for patients with rapidly progressive disease ${ }^{199}$.

In the ALADIN study on kidney and cyst growth, patients with ADPKD were randomly assigned to octreotide (a long-acting somatostatin analogue that also decreases cAMP levels) or placebo treatment groups, and a favourable trend of reduced TKV increase and eGFR decline was observed, although statistical significance was not reached and thus larger trials are required ${ }^{200}$. DIPAK1 and LIPS are ongoing clinical trials to evaluate the effect of the somatostatin analogue lanreotide on disease progression in patients with ADPKD and stage 3 CKD or stage 2-3 CKD, respectively. Clinical trials of the mTOR inhibitors sirolimus and everolimus failed to show benefit despite encouraging results in animal models ${ }^{201-203}$, which is probably owing to an inability to administer sufficient levels of these drugs to inhibit mTOR in the kidneys without causing systemic toxic effects. Pravastatin, an HMGCoA reductase inhibitor, has shown promising results in slowing cyst growth in a small randomized clinical trial in children with $\mathrm{ADPKD}^{204}$.

Cyst growth and disease monitoring.-Cyst development and growth varies widely between patients. Furthermore, even in patients with severe disease, GFR remains within the normal range for decades, limiting its value to estimate the prognosis or monitor the progression of the disease in its early stages. TKV correlates with disease manifestations such as hypertension, pain, haematuria and proteinuria ${ }^{159}$; TKV and cyst volume increase exponentially but at variable rates, averaging 5-6\% per year. Accordingly, measurement of $\mathrm{TKV}$ is beneficial if the data could influence a medical decision, such as enrolment in a clinical trial or initiation of treatment in countries in which medications are approved for the treatment of ADPKD. MRI is the preferred method to measure TKV, as it is more accurate than ultrasonography and safer than CT, but its cost may be a limitation in some countries.

Hypertension.-A recent meta-analysis concluded that at least $20 \%$ of children with ADPKD have hypertension and that many of those children are undiagnosed and do not attend regular follow-ups ${ }^{177}$. A recent retrospective multicentre study of ambulatory blood pressure monitoring even found a higher prevalence of hypertension in children with ADPKD $^{176}$. In this study, $31 \%, 42 \%$ and $35 \%$ of a cohort of 310 children with ADPKD (mean age $11.5 \pm 4.1$ years) were hypertensive during the daytime, the night-time or the entire 24-hour cycle, respectively. More than half of the patients (52\%) lacked physiological nocturnal blood pressure dipping. Thus, children with a family history of ADPKD should be screened regularly for hypertension from the age of 5 years and at 3-year intervals when no hypertension is found. The HALT PKD placebo-controlled clinical trial examined the role of blockade of the RAAS in patients with early and advanced ADPKD. In patients with early 
ADPKD (15-49 years of age, eGFR $>60 \mathrm{ml} / \mathrm{min} / 1.73 \mathrm{~m}^{2}$ ), rigorous blood pressure control (blood pressure target range $95 / 60$ to $110 / 75 \mathrm{mmHg}$ ) was associated with slower rates of increase in TKV and renal vascular resistance and with a greater decline in left ventricular mass index (faster during the first 4 months and slower decline there-after), without an overall effect on eGFR, than standard blood pressure control (120/70 to 130/80 $\mathrm{mmHg})^{205,206}$. Rigorous blood pressure control was not studied in patients with more advanced ADPKD (18-64 years of age, eGFR 25-60 ml/min/1.73 $\mathrm{m}^{2}$ ) because it was considered to be detrimental in these patients ${ }^{207}$. At both early and late stages of the disease, monotherapy with an angiotensin-converting-enzyme (ACE) inhibitor achieved good blood pressure control ( $<130 / 85 \mathrm{mmHg}$ ) in most patients. Therefore, ACE inhibitors (or angiotensin receptor blockers (ARBs)) are considered to be the first-line therapy for hypertension in ADPKD.

Pain.-At least $60 \%$ of patients with ADPKD eventually experience acute or chronic abdominal or flank pain of renal origin. Acute pain is often associated with kidney cyst haemorrhage, infection or nephrolithiasis (kidney stones). Chronic pain is usually attributable to cyst enlargement that causes kidney capsule stretching or to marked enlargement of the kidneys and/or liver that causes musculoskeletal back pain. Managing chronic pain can be challenging and requires a multidisciplinary stepwise approach with multiple strategies, including physical therapy interventions, pain medications, cyst sclerosis and laparoscopic cyst fenestrations and renal denervation procedures ${ }^{208-210}$.

Haematuria.-Gross haematuria may be associated with cyst haemorrhage or infection, passage of kidney stones or kidney or urinary tract neoplasms. Cyst haemorrhage can be associated with fever, which might be difficult to differentiate from cyst infection. With conservative management (rest, holding anticoagulants or antiplatelet drugs, and analgesics if needed), most haemorrhages resolve within 2-7 days. If symptoms persist for $>1$ week or if the initial episode occurs after the age of 50 years, investigation to exclude neoplasm should be undertaken. The management of gross haematuria is mostly conservative - rest, hydration and avoidance or temporary holding of medications that facilitate bleeding. The antifibrinolytic agent tranexamic acid can be considered when conservative therapy fails ${ }^{211}$. Selective arterial embolization or nephrectomy may be necessary in cases of life-threatening haemorrhage.

Nephrolithiasis.-Increased frequency of nephrolithiasis in patients with ADPKD is attributed to increased urinary stasis and metabolic factors, which include low urinary $\mathrm{pH}$, low citrate concentration and decreased ammonia excretion. These factors predispose to the development of uric acid and calcium oxalate stones. The medical treatment of nephrolithiasis in patients with ADPKD is similar to that in the general population; for example, extracorporeal shock wave lithotripsy and percutaneous nephrolithotomy in patients with early disease and normal kidney function have been used successfully without increased risk of complications ${ }^{212}$. Flexible ureterorenoscopy with laser fragmentation has also been used successfully ${ }^{213}$. 
Cyst infection.-The triad of abdominal or flank pain and/or tenderness, fever and elevated erythrocyte sedimentation rate or C-reactive protein (CRP) should raise suspicion of cyst infection. Initial evaluation should include urinalysis, urine culture with antimicrobial susceptibility testing, blood culture and imaging with CT scan or MRI ${ }^{214,215}$. When available, an ${ }^{18}$ F-fluorodeoxyglucose (FDG)-PET scan is more sensitive than CT or MRI for detecting cyst infections ${ }^{216}$. If a complex cyst (that is, a cyst that does not meet the diagnostic criteria of a benign simple cyst) is detected, aspiration of cyst fluid should be considered if clinically feasible and the fluid should be sent for microbiology studies. Treatment of cyst infections should include intravenous broad-spectrum antibiotics if the patient has systemic symptoms, followed by a transition to oral antibiotics that have good cyst penetration, such as ciprofloxacin or other quinolones (total duration of antibiotic treatment should be at least 4 weeks). If the fever persists unabated for $>72$ hours, repeat imaging should be obtained to exclude complications that may require intervention (for example, perinephric abscess or urinary tract obstruction). Infected cysts $>5 \mathrm{~cm}$ may be resistant to antibiotic therapy and require percutaneous or surgical drainage ${ }^{217}$. Perinephric abscess requires prolonged intravenous antibiotic therapy and drainage should be considered. Nephrectomy is rarely needed but may be considered in cases of perinephric abscess or emphysematous pyelonephritis that are resistant to drainage and/or antibiotic therapy $^{218}$.

Renal cell carcinoma.-A high index of suspicion is required to make the diagnosis of renal cell carcinoma (RCC) in the rare cases when a tumour develops in a polycystic kidney, as RCC does not occur more frequently in ADPKD than in other renal diseases ${ }^{219}$. Rapid growth of a complex cyst, a solid mass on ultrasonography, speckled calcifications on CT imaging, contrast enhancement, tumour thrombus and regional lymphadenopathies on CT or MRI scans should raise suspicion of RCC. Fever and systemic symptoms (anorexia, fatigue and weight loss) are frequent presenting symptoms ${ }^{220}$. Nephronsparing interventions should be used whenever feasible and safe 221 .

\section{ESRD.}

Kidney transplantation is the optimal kidney replacement treatment and the results in ADPKD patients are better than in the general ESRD population ${ }^{222}$. Given the natural course of the disease, preemptive transplantation can be planned and is associated with better outcomes. Radical nephrectomy for space considerations is carried out in $20-25 \%$ of patients with ADPKD and may be done before, at the time of or several months after the transplantation. During the first year following a successful kidney transplantation, the volume of the native polycystic kidneys decreases by $30-40 \% 223$ for reasons that are unclear but might include reduced blood flow and resolution of uraemic factors that stimulate renal growth. Indications for nephrectomy also include recurrent and/or severe infection, bleeding, intractable pain, symptomatic nephrolithiasis and suspicion of kidney malignancy. Handassisted laparoscopic nephrectomy is less invasive than an open approach and the preferred timing varies between centres ${ }^{224}$.

Although ADPKD is not a contraindication for peritoneal dialysis ${ }^{225}$, it is less commonly used than haemo-dialysis given the challenge of accommodating a large volume of 
peritoneal dialysate and an increased risk of abdominal wall hernias. In haemodialysis treatment, patients with ADPKD may have an increased risk of aneurysmal dilatation of arteriovenous fistulas $^{225}$.

Hepatic cysts.-In the majority of patients with ADPKD, liver cysts remain asymptomatic. Because of the increased survival of patients with ADPKD on RRT, the prevalence of clinically significant PLD is increasing ${ }^{226}$. Manifestations of PLD may be due to mass effects from organomegaly or cyst complications such as haemorrhage, infection or rupture. In addition to female sex, the main risk factors for severe PLD include multiple pregnancies and prolonged use of estrogens and, possibly, progestogens ${ }^{227}$.

Surgical interventions for severe PLD should target symptom alleviation and improvement of QOL and should be tailored to the characteristics of individual patients and to the natural history of PLD ${ }^{68}$. Surgical options include percutaneous aspiration and sclerosis with ethanol or other agents, deroofing of cysts laparoscopically or by open surgery and combined liver resection and cyst fenestration ${ }^{228}$. The latter procedure should be reserved for patients with severe symptomatic PLD and a liver anatomy that allows the preservation of at least two contiguous liver segments with adequate hepatic venous drainage ${ }^{229}$. Transcatheter arterial embolization results in only a modest volume reduction and is associated with substantial morbidity and mortality ${ }^{230,231}$. Liver transplantation is considered for patients when partial liver resection is not feasible. Somatostatin analogues, such as octreotide and lanreotide, can reduce liver cyst volume ${ }^{232-236}$.

Liver cyst infections are a common complication of PLD and are diagnosed, evaluated and managed similarly to infected kidney cysts. Diverticular disease and ascending cholangitis should be considered as a possible source of liver cyst infections. The presentation of ascending cholangitis is characterized by cholestasis with elevation of conjugated bilirubin. Some patients may experience recurrent episodes of cholangitis that may be difficult to treat, sometimes requiring monthly rotating antibiotics to prevent recurrences. Endoscopic sphincterotomy may increase the risk of recurrent cholangitis and should be avoided if possible. It is important to recognize that mild dilatation of the extrahepatic common bile duct can be observed in up to $40 \%$ of patients with ADPKD and should not lead to an unnecessary and dangerous sphincterotomy ${ }^{237}$.

Intracranial aneurysms.-ICAs are detected in $\sim 8 \%$ of patients with ADPKD, which is approximately fivefold higher than in the general population but is further increased (approximately threefold higher) in patients with a relative who has had an ICA ${ }^{238}$.

The rupture of ICAs is associated with a mortality of up to $50 \%$ and a mean age at rupture of 40 years, which is lower than in the general population ${ }^{238}$. Rupture usually presents as sudden onset of a severe headache (described as a thunder clap headache). Increased size, posterior location, family history of ICAs and a personal history of subarachnoid haemorrhage are potential risks for rupture. The management of unruptured ICAs is the same as that in the general population ${ }^{69,239,240}$. 
Given the frequency of ICAs in patients with ADPKD and that they increase morbidity and mortality risk, whether patients with ADPKD should undergo presymptomatic screening for ICAs has been intensely debated and universal consensus has not been reached ${ }^{239,241}$. The majority of ICAs that were detected by presymptomatic screening in patients with ADPKD (which is generally carried out using magnetic resonance angiography (MRA)) are $<7 \mathrm{~mm}$ in diameter and are in the anterior circulation (80-90\% of cases), which in the general population have a very small risk of rupture ${ }^{239}$. Few longitudinal studies of asymptomatic, unruptured ICAs in patients with ADPKD have been carried out, but the few that have suggest that their natural history is not different from that of ICAs in the general population 69,242 . Accordingly, although we do not recommend presymptomatic screening for all patients with ADPKD, screening might be appropriate in patients with a family history of aneurysmal rupture owing to the higher prevalence of unruptured ICAs and possible increased risk of rupture 243,244 . Screening may also be appropriate in patients with ADPKD who have a family history of ICAs and a personal history of intracranial haemorrhage, as well as in individuals in high-risk professions such as pilots and before major elective surgeries. Given the substantial risk of intervention, it is our opinion that treatment is not usually recommended for ICAs $<7 \mathrm{~mm}$ in size; the frequency of follow-up MRAs for smaller ICAs depends on information about stability. If screening is negative, rescreening of patients with good life expectancy at 5-year intervals seems reasonable in our opinion. MRA for the detection of ICAs does not require administration of gadolinium and is preferable to CT angiography (CTA), especially in patients with reduced eGFR to avoid iodinated contrast ${ }^{245}$.

\section{ARPKD}

In the most severe cases of ARPKD, poor urine output in utero results in oligohydramnios (deficiency of amniotic fluid) and Potter sequence. The ARPKD presentation at birth may be dominated by respiratory difficulties from pulmonary hypoplasia and/or from restrictive disease caused by massive kidney enlargement ${ }^{1}$. In patients with respiratory insufficiency, the cause should be identified and aggressive resuscitative measures, including artificial ventilation if needed, should be implemented. In some severe cases, unilateral or bilateral nephrectomies may be considered, although the evidence to support this approach has been questioned ${ }^{183,246}$. In patients who survive infancy, renal function may improve or remain stable for many years and slowly progress to renal failure only later in life as the kidneys develop macroscopic cysts and interstitial fibrosis, and the size ofthe kidneys relative to body mass often decreases ${ }^{182,183}$.

Hypertension.-Arterial hypertension often develops during the first months of life and affects up to $80 \%$ of children with ARPKD ${ }^{32}$. Although arterial hypertension is sometimes difficult to control, even with multidrug treatment, it generally responds well to salt restriction and antihypertensive drugs (preferably an ACE inhibitor or ARB). After the first year of life, hypertension may become easier to control for reasons that are still poorly understood.

Electrolyte, nutritional and growth abnormalities.-Electrolyte abnormalities due to the inability to concentrate and dilute urine are very common in the early, severe 
presentations of ARPKD and should be anticipated and treated ${ }^{183}$. An assertive nutritional programme and correction of acidosis are important to optimize linear renal growth. If renal growth impairment occurs, treatment with growth hormone can be considered ${ }^{247}$.

ESRD.-For infants with ESRD, peritoneal dialysis or haemodialysis can be used. Renal transplantation is limited by body size, but in centres that are well experienced in paediatric surgery, it can be carried out even in small children with a minimum weight of $7 \mathrm{~kg}^{248,249}$. Rejection rates and survival beyond 3 years of age are not different from patients with most other renal diseases who undergo transplant surgery. Biliary sepsis can cause mortality in patients with ARPKD after renal transplantation ${ }^{249}$.

Congenital hepatic fibrosis.-Although CHF invariably occurs in children with ARPKD and can be associated with non-obstructive intrahepatic bile duct dilatation (Caroli disease), clinical manifestations of portal hypertension typically manifest as the children age. Some adolescents and adults without a previous diagnosis of ARPKD may present with hepatic manifestations, most often with complications of portal hypertension (such as variceal oesophageal bleeding, splenomegaly and hypersplenism with leukopenia, thrombocytopenia or anaemia) or episodes of cholangitis or sepsis and complications of biliary sludge or lithiasis. Liver enzyme values can occasionally be mildly elevated, but hepatocellular function is usually normal. The kidneys in these patients may be normal or exhibit varying degrees of medullary collecting duct ectasia or macrocystic disease without marked renal enlargement. Patients with ARPKD who survive infancy and those who present during adolescence may require a portosystemic shunt to prevent life-threatening haemorrhages from oesophageal varices. Patients with associated Caroli disease might have recurrent episodes of cholangitis. Although routine antibiotic prophylaxis for cholangitis is not recommended, antibiotic prophylaxis for 6-12 weeks after a cholangitis episode, immediately after transplantation or in the context of increased immunosuppression may be considered ${ }^{249}$. Adult patients with ARPKD $>40$ years of age may have a slightly increased risk of developing hepatic tumours, especially cholangiocarcinomas ${ }^{250}$.

Combined kidney and liver transplantation has been advocated for selected patients with ESRD who have substantial bile duct dilatation and episodes of cholangitis ${ }^{251-253}$. In addition to primary hyperoxaluria, ARPKD can certainly be considered an indication for combined liver and kidney transplantation during childhood. The best timing and strategy for combined transplantation is still a matter of debate and usually requires decision-making based on individual circumstances.

\section{Quality of life}

In the personalized medicine approach, it is no longer sufficient to treat the disease instead, clinicians must treat their patients. Consequently, disease management paradigms should include biological, physical and psychological assessments, which seems to be particularly important for patients with multifaceted diseases such as ADPKD and further underscores the importance of including patient-reported outcomes in routine clinical care. In parallel, sensitive and appropriate kidney disease measures should be developed alongside other established tools to assess the burden of ADPKD in an individualized, personalized 
manner. Health-related QOL (HRQOL), which encompasses physical and mental health, social issues as well as pain and discomfort ${ }^{254}$, facilitates patient-centred care and encourages shared decision-making among medical professionals and patients. The specific issues of QOL have not been systemically studied in patients with ARPKD or their families; accordingly, we focus on only ADPKD.

ADPKD affects the biological, physical and psychological aspects of patient QOL. For example, physicians underestimate the effect of renal pain in patients with ADPKD, despite its high prevalence in patients with chronic kidney diseases ${ }^{255}$. Pain and abdominal fullness, which are both common symptoms of ADPKD, are often associated with lower eGFR ${ }^{256}$. Furthermore, pain is independently associated with clinical depression ${ }^{257}$, and although evidence exists that depression is common among patients with ADPKD ${ }^{257}$, studies that explicitly address the treatment of depression in patients with ADPKD are lacking. Accordingly, HRQOL assessment might help guide treatment decisions. Indeed, HRQOL scores have been shown to predict risk of increased hospitalization and mortality in patients with chronic kidney diseases ${ }^{258}$. However, only a limited number of HRQOL studies of patients with ADPKD have analysed possible correlations between disease progression, psychosocial burden and their effect on daily living.

Generic QOL measures (such as the 36-item Short Form Health Survey (SF-36)) are fairly insensitive, especially in patients with early-stage $\mathrm{ADPKD}^{255,256,259}$. In a recent study of HRQOL in patients with ADPKD who encompassed all stages of the disease (from patients with early CKD to those on dialysis or undergoing renal transplantation), overall HRQOL was generally highest in patients with CKD stage $1-3$, followed by renal transplant recipients, patients with stage 4-5 CKD and patients on dialysis ${ }^{255}$. Progressive disease predominantly had an effect on physical health, whereas mental health varied less between patients with different stages of the disease ${ }^{255}$.

A new self-administered patient-reported outcome questionnaire, the ADPKD Impact Scale (ADPKD-IS), which consists of 14 items representing 3 conceptual domains (physical, emotional and fatigue) and 4 additional questions, was developed on the basis of the information (see below) of 1,674 patients worldwide ${ }^{260}$. The ADPKD-specific conceptual framework (a model representing concepts and themes to be measured and their relationships) in this questionnaire was created on the basis of information from patients and clinical experts about how ADPKD affected the general health, daily activities, physical or social activities, pain experience, urinary issues (such as urgency and frequency of urination as well as nocturia) and emotional well-being of patients. Scores on the physical, emotional and fatigue domains of the ADPKD-IS differed substantially between patients with stage $3 b$ CKD versus those with stage 1 CKD at baseline ${ }^{260}$.

Of note, effective treatment of ADPKD can improve HRQOL — a 1-year trial with octreotide resulted in modestly reduced liver volumes $(4.95 \% \pm 6.77 \%)$ and was associated with improvements in pain and emotional scales on the SF-36 (REF. ${ }^{234}$ ). Perceived social support and the psychosocial impact of coping with a diagnosis of ADPKD were analysed in another cross-sectional study ${ }^{257}$, which found that lower eGFR was associated with less perceived social support. Depression, increased kidney size and loss of a first-degree relative 
to ADPKD were identified as independent risk factors for increased psychosocial risk. Of note, women were more likely to be predisposed to poorer overall psychosocial well-being than $\operatorname{men}^{257}$.

Given the genetic basis of ADPKD, patients are often faced with major psychological challenges related to the hereditary nature of the disorder and its potential effect on their family and offspring. 'Genetic guilt' may be the reason many patients hide their diagnosis from their spouse and family, even when these people are usually central to their emotional support network. Hidden genetic guilt substantially affects the psychosocial well-being of patients $^{261}$.

\section{Outlook}

Although the prospects for better outcome predictions and treatments have dramatically improved over the past decade, an incomplete understanding of the function of the polycystin proteins remains a substantial impediment to understanding the pathogenesis of PKD and developing rational therapies to treat these diseases. For ARPKD in particular, the limitations of experimental models and the paucity of biomarkers and imaging modalities to enable prediction of the disease course limit current efforts to design clinical trials to test the efficacy of potential new therapies.

\section{Pathogenesis}

The greatest challenge in research on PKD, and that which is likely to be of greatest benefit if overcome, is understanding the pathogenesis of PKD. Although the aetiologies of ADPKD and ARPKD are mostly understood, many questions about the pathogenesis of these diseases are still intensely disputed. For example, although PC2 is a TRP-like calcium channel, a definite role for $\mathrm{Ca}^{2+}$ in the pathogenesis of ADPKD has not been established, and the role of PC2 as a chaperone for PC1 may be important ${ }^{262,263}$. The role of somatic changes at the disease-causing locus in cystic epithelia, which are required for cyst initiation and, more importantly, for cyst expansion and/or persistence, is another highly debated area of research that would benefit from additional studies ${ }^{56,62,63,264}$.

The ciliary basis of PKD pathogenesis has been the predominant hypothesis for $>15$ years, but studies have cast doubt on this hypothesis. The proposed ciliary localization (among others) of PC1, PC2, fibrocystin and DZIP1L ${ }^{132,145}$ and the observations that a loss of ciliary function 265 or the abnormal ciliary composition in some syndromic ciliopathies ${ }^{266,267}$ cause PKD are the strongest evidence supporting the cilia hypothesis. However, the role of the polycystin complex in cilia is not clear; for example, the hypothesis that the polycystin complex functions as a mechanosensor in cilia is not supported by recent data $^{86,87}$. Indeed, despite a study suggesting that the polycystin complex is a WNT receptor, the function of the polycystin complex in healthy tissue seems far from resolved and this uncertainty remains a major impediment to understanding the pathogenesis of $\mathrm{ADPKD}^{268}$. As discussed earlier, cilia certainly have a role in PKD, as concomitant ablation of $P k d 1$ and loss of cilia in mice results in less severe cystic disease than ablation of $P k d 1$ alone ${ }^{103}$. Alternatively, separate cystic (polycystin complex-related) and proliferation pathways required for cystic growth are ciliary-based. In fact, the ciliary localization of PC1 has been 
questioned (a specific stimulus might be required for PC1 to get to the cilium), and other polycystin-like proteins (such as PKD1-like protein 1 (PKD1L1) and PKD2L1), rather than PC1 and PC2, might regulate ciliary $\mathrm{Ca}^{2+}$ levels ${ }^{87,269,270}$. In addition, conflicting data exist about whether calcium influx into the cilium is sufficient to activate a cytoplasmic calcium response ${ }^{87,271}$.

Although a ciliary function has been proposed for both fibrocystin and DZIP1L, and genetic studies suggest that they are associated with the polycystin complex ${ }^{121,132}$, the precise role of these proteins remains unresolved. That fibrocystin seems much more important for kidney tubule integrity in humans than in mice further complicates experimental resolution $^{272,273}$. The functions of PC1, PC2, fibrocystin and DZIP1L, or those of the cleavage products of these proteins, when secreted into urine in soluble form ${ }^{148}$ or in urinary extracellular vesicles exocytosed by the multivesicular body pathway ${ }^{274}$, or even possibly from cilia $^{275}$, require further study. Other unresolved questions include whether the $\mathrm{C}$ terminus of PC1 (and fibrocystin) is cleaved and translocates to the nucleus, how much it contributes to the signalling by the polycystin complex and whether it is relevant for preventing $\mathrm{PKD}^{276}$. Additionally, ciliary-based signalling, such as that mediated by sonic hedgehog, has also been suggested to be important in PKD, although its precise role in ADPKD and ARPKD is not clear ${ }^{277}$.

\section{Diagnosis and prognosis}

Further research is necessary to improve the identification of patients who require treatment and especially the monitoring of treatment efficacy. It is widely accepted that current methods to monitor kidney function are not very useful for diagnosis in the early stages of disease when treatment is likely to be the most efficacious. Determination of htTKV by imaging is currently the best method to predict disease outcomes and to monitor treatment efficacy, and further quantitative image analysis of kidney composition is likely to improve its predictive and monitoring value ${ }^{278}$. Research to identify potential biochemical biomarkers is still in the early stages, but with an easily accessible supply of urine from patients to monitor kidney function, it seems likely that this area of research is ripe for development ${ }^{279,280}$. Together with the present genic and allelic predictive value of the germline mutation, better in silico analyses and cellular assays should enable the identity and penetrance of in-frame mutations to be more accurately predicted ${ }^{262}$. Other genetic factors that are associated with disease progression (identified using genome-wide association studies, WES and WGS) are also likely to be of prognostic value and to improve our understanding of the pathogenesis of $\mathrm{PKD}^{79}$.

\section{Therapies}

This is an exciting time for PKD studies, as the first drug specifically for the treatment ADPKD, tolvaptan, has received regulatory approval in many parts of the world ${ }^{179,197}$. It seems likely that other treatments targeting signalling pathways downstream of PKDcausing genetic lesions, including inhibitors of cAMP generation (for example, somatostatin analogues such as octreotide ${ }^{200}$ ), more effective inhibitors of mTOR activity in the kidneys (for example, rapamycin conjugates ${ }^{281}$ ), remedying metabolic abnormalities (for example, by food restriction ${ }^{282}$ ) and other therapies that were effective in rodent studies (for example, 
reducing inflammation or calcium signalling; reviewed elsewhere ${ }^{33}$ ), are likely to be approved for human treatment in the next few years. There are prospects for combination treatments $^{283}$, and some of these therapies may also be effective in treating severe PLD ${ }^{284}$. Furthermore, although the development of treatments that more directly target the basic defect (deficiency of PCI or PC2) in PKD has not been undertaken, evidence exists for other genetic diseases that this approach could be productive ${ }^{285-287}$. These treatments could include chaperone treatment for some missense mutations ${ }^{288}$, targeting nonsense mutations using translational readthrough-inducing drugs ${ }^{289}$, boosting the levels of functional $\mathrm{PC} 1$ and somatic gene editing using CRISPR-Cas9 $\left(\mathrm{REF}^{290}\right.$ ) to repair the underlying defect in the kidneys. To date, little progress has been made in developing treatments for ARPKD, but given the related disease mechanisms in ADPKD and ARPKD, there is the hope that at least some therapies for ADPKD might also be effective in treating ARPKD.

\section{Acknowledgements}

C.B. receives research support for his laboratory from the Deutsche Forschungsgemeinschaft (DFG) Collaborative Research Centre (SFB) KIDGEM 1140 and the Federal Ministry of Education and Research (BMBF, 01GM1515C). L.M.G.-W. is supported by US National Institute of Diabetes and Digestive and Kidney Diseases (NIDDK) funding of the University of Alabama-Birmingham Hepato-Renal Fibrocystic Disease Core Center (DK074038). D.J.M.P. receives financial support from the Dutch Kidney Foundation and the Netherlands Organisation for Scientific Research. S.H. is supported by the Japan Society for the Promotion of Science KAKENHI grant number JP15K10632. P.C.H. and V.E.T. are supported by NIDDK funding of the Mayo Translational Polycystic Kidney Disease Center (DK090728). The authors thank J. Smith, T. Kline and M. Edwards (all at the Mayo Clinic, MN, USA) for their assistance with figures 1 and 7.

\section{References}

1. Bergmann C ARPKD and early manifestations of ADPKD: the original polycystic kidney disease and phenocopies. Pediatr. Nephrol. 30, 15-30 (2015). [PubMed: 24584572]

2. Torres VE, Harris PC \& Pirson Y Autosomal dominant polycystic kidney disease. Lancet 369 , 1287-1301 (2007). [PubMed: 17434405]

3. Bergmann C \& Weiskirchen R It's not all in the cilium, but on the road to it: genetic interaction network in polycystic kidney and liver diseases and how trafficking and quality control matter. $\mathrm{J}$. Hepatol.56, 1201-1203 (2012). [PubMed: 22133568]

4. Gerdes JM, Davis EE \& Katsanis N The vertebrate primary cilium in development, homeostasis, and disease. Cell 137, 32-45 (2009). [PubMed: 19345185]

5. Hildebrandt F, Benzing T \& Katsanis N Ciliopathies. N. Engl. J. Med. 364, 1533-1543 (2011). [PubMed: 21506742]

6. Dalgaard OZ Bilateral polycystic disease of the kidneys; a follow-up of two hundred and eighty-four patients and their families. Acta Med. Scand. Suppl. 328, 1-255 (1957). [PubMed: 13469269]

7. Iglesias CG et al. Epidemiology of adult polycystic kidney disease, Olmsted County, Minnesota: 1935-1980. Am. J. Kidney Dis. 2, 630-639 (1983). [PubMed: 6846334]

8. Levy M \& Feingold J Estimating prevalence in single-gene kidney diseases progressing to renal failure. Kidney Int. 58, 925-943 (2000). [PubMed: 10972657]

9. Davies F et al. Polycystic kidney disease re-evaluated: a population-based study. Q. J. Med. 79, 477485 (1991). [PubMed: 1946928]

10. Simon $P$ et al. [Epidemiologic data, clinical and prognostic features of autosomal dominant polycystic kidney disease in a French region]. Nephrologie 17, 123-130 (1996). [PubMed: 8838759]

11. Yersin $\mathrm{C}$ et al. Frequency and impact of autosomal dominant polycystic kidney disease in the Seychelles (Indian Ocean). Nephrol. Dial. Transplant. 12, 2069-2074 (1997). [PubMed: 9351067]

12. Higashihara $E$ et al. Prevalence and renal prognosis of diagnosed autosomal dominant polycystic kidney disease in Japan. Nephron 80, 421-427 (1998). [PubMed: 9832641] 
13. de Almeida E et al. Prevalence of autosomaldominant polycystic kidney disease in Alentejo. Portugal. Kidney Int. 59, 2374 (2001). [PubMed: 11380844]

14. Neumann HP et al. Epidemiology of autosomal-dominant polycystic kidney disease: an in-depth clinical study for south-western Germany. Nephrol. Dial. Transplant. 28, 1472-1487 (2013). [PubMed: 23300259]

15. McGovern AP et al. Identification of people with autosomal dominant polycystic kidney disease using routine data: a cross sectional study. BMC Nephrol.15, 182 (2014). [PubMed: 25412767]

16. Willey CJ et al. Prevalence of autosomal dominant polycystic kidney disease in the European Union. Nephrol. Dial. Transplant. 32, 1356-1363 (2017). [PubMed: 27325254]

17. Chan KW Adult polycystic kidney disease in Hong Kong Chinese: an autopsy study. Pathology 25, 229-232 (1993). [PubMed: 8265237]

18. Cornec-Le Gall E, Torres VE \& Harris PC Genetic complexity of autosomal dominant polycystic kidney and liver diseases. J. Am. Soc. Nephrol. 29, 13-23 (2018). [PubMed: 29038287]

19. Wakai K et al. Trends in incidence of end-stage renal disease in Japan, 1983-2000: age-adjusted and age-specific rates by gender and cause. Nephrol. Dial. Transplant. 19, 2044-2052 (2004). [PubMed: 15173379]

20. The United States Renal Data System (USRDS).USRDS 1999 Annual Data Report (National Institute of Diabetes and Digestive and Kidney Diseases,1999).

21. Stengel B et al. Trends in the incidence of renal replacement therapy for end-stage renal disease in Europe, 1990-1999. Nephrol. Dial. Transplant. 18, 1824-1833 (2003). [PubMed: 12937231]

22. Parfrey PS et al. The diagnosis and prognosis of autosomal dominant polycystic kidney disease.N. Engl. J. Med. 323, 1085-1090 (1990). [PubMed: 2215575]

23. Simon P Prognosis of autosomal dominant polycystic kidney disease. Nephron 71, 247-248 (1995). [PubMed: 8569973]

24. Spithoven EM et al. Analysis of data from the ERA-EDTA registry indicates that conventional treatments for chronic kidney disease do not reduce the need for renal replacement therapy in autosomal dominant polycystic kidney disease. Kidney Int. 86, 1244-1252 (2014). [PubMed: 24827775]

25. Shaw C, Simms RJ, Pitcher D \& Sandford R Epidemiology of patients in England and Wales with autosomal dominant polycystic kidney disease and end-stage renal failure. Nephrol. Dial. Transplant. 29, 1910-1918 (2014). [PubMed: 24737444]

26. Alzarka B, Morizono H, Bollman JW, Kim D \& Guay-Woodford LM Design and Implementation of the Hepatorenal Fibrocystic Disease Core Center Clinical Database: a centralized resource for characterizing autosomal recessive polycystic kidney disease and other hepatorenal fibrocystic diseases. Front. Pediatr. 5, 80 (2017). [PubMed: 28473971]

27. Kääriäinen H Polycystic kidney disease in children: a genetic and epidemiological study of 82 Finnish patients. J. Med. Genet. 24, 474-481 (1987). [PubMed: 3656369]

28. Bergmann C \& Zerres K Early manifestations of polycystic kidney disease. Lancet 369, 2157 (2007).

29. Guay-Woodford LM \& Desmond RA Autosomal recessive polycystic kidney disease: the clinical experience in North America. Pediatrics 111, 1072-1080 (2003). [PubMed: 12728091]

30. Bergmann $\mathrm{C}$ et al. PKHD1 mutations in families requesting prenatal diagnosis for autosomal recessive polycystic kidney disease (ARPKD). Hum. Mutat. 23, 487-495 (2004). [PubMed: 15108281]

31. Gimpel $\mathrm{C}$ et al. Perinatal diagnosis, management, and follow-up of cystic renal diseases: a clinical practice recommendation with systematic literature reviews. JAMA Pediatr. 172, 74-86 (2018). [PubMed: 29181500]

32. Bergmann $\mathrm{C}$ et al. Clinical consequences of PKHD1 mutations in 164 patients with autosomalrecessive polycystic kidney disease (ARPKD). Kidney Int. 67, 829-848 (2005). [PubMed: 15698423]

33. Harris PC \& Torres VE Genetic mechanisms and signaling pathways in autosomal dominant polycystic kidney disease (ADPKD). J. Clin. Invest. 124, 2315-2324 (2014). [PubMed: 24892705] 
34. Porath B et al. Mutations in GANAB, encoding the glucosidase Ila subunit, cause autosomaldominant polycystic kidney and liver disease. Am. J. Hum. Genet. 98, 1193-1207 (2016). [PubMed: 27259053]

35. Besse $\mathrm{W}$ et al. Isolated polycystic liver disease genes define effectors of polycystin-1 function. J. Clin. Invest. 127, 3558 (2017). [PubMed: 28862642]

36. Cornec-Le Gall E et al. Monoallelic mutations to DNAJB11 cause atypical autosomal-dominant polycystic kidney disease. Am. J. Hum. Genet. 102, 832-844 (2018). [PubMed: 29706351]

37. Drenth JP, Te Morsche RH, Smink R, Bonifacino JS \& Jansen JB Germline mutations in PRKCSH are associated with autosomal dominant polycystic liver disease. Nat. Genet. 33, 345-347 (2003). [PubMed: 12577059]

38. Davila S et al. Mutations in SEC63 cause autosomal dominant polycystic liver disease. Nat. Genet. 36, 575-577 (2004). [PubMed: 15133510]

39. Li A et al. Mutations in PRKCSH cause isolated autosomal dominant polycystic liver disease. Am. J. Hum. Genet. 72, 691-703 (2003). [PubMed: 12529853]

40. Cnossen WR et al. Whole-exome sequencing reveals LRP5 mutations and canonical Wnt signaling associated with hepatic cystogenesis. Proc. Natl Acad. Sci. USA 111, 5343-5348 (2014). [PubMed: 24706814]

41. Gunay-Aygun $\mathrm{M}$ et al. Hepatorenal findings in obligate heterozygotes for autosomal recessive polycystic kidney disease. Mol. Genet. Metab. 104, 677-681 (2011). [PubMed: 21945273]

42. Hart TC et al. Mutations of the UMOD gene are responsible for medullary cystic kidney disease 2 and familial juvenile hyperuricaemic nephropathy. J. Med. Genet. 39, 882-892 (2002). [PubMed: 12471200]

43. Kirby A et al. Mutations causing medullary cystic kidney disease type 1 lie in a large VNTR in MUC1 missed by massively parallel sequencing. Nat. Genet. 45, 299-303 (2013). [PubMed: 23396133]

44. Chapman AB et al. Autosomal dominant polycystic kidney disease (ADPKD): executive summary from a Kidney Disease: Improving Global Outcomes (KDIGO) Controversies Conference. Kidney Int. 88, 17-27 (2015). [PubMed: 25786098]

45. Bolar NA et al. Heterozygous loss-of-function SEC61A1 mutations cause autosomal-dominant tubulo-interstitial and glomerulocystic kidney disease with anemia. Am. J. Hum. Genet. 99, 174187 (2016). [PubMed: 27392076]

46. Plaisier E et al. COL4A1 mutations and hereditary angiopathy, nephropathy, aneurysms, and muscle cramps. N. Engl. J. Med. 357, 2687-2695 (2007). [PubMed: 18160688]

47. Bergmann C Recent advances in the molecular diagnosis of polycystic kidney disease. Expert Rev.Mol. Diagn. 17, 1037-1054 (2017).

48. Hughes $\mathrm{J}$ et al. The polycystic kidney disease 1 (PKD1) gene encodes a novel protein with multiple cell recognition domains. Nat. Genet. 10, 151-160 (1995). [PubMed: 7663510]

49. Qian F et al. Cleavage of polycystin-1 requires the receptor for egg jelly domain and is disrupted by human autosomal-dominant polycystic kidney disease 1-associated mutations. Proc. Natl Acad. Sci. USA 99, 16981-16986 (2002). [PubMed: 12482949]

50. Kurbegovic A et al. Novel functional complexity of polycystin-1 by GPS cleavage in vivo: role in polycystic kidney disease. Mol. Cell. Biol. 34, 3341-3353 (2014). [PubMed: 24958103]

51. Low SH et al. Polycystin-1, STAT6, and P100 function in a pathway that transduces ciliary mechanosensation and is activated in polycystic kidney disease. Dev. Cell 10, 57-69 (2006). [PubMed: 16399078]

52. $\mathrm{Xu}$ Y et al. The polycystin-1, lipoxygenase, and a-toxin domain regulates polycystin-1 trafficking. J. Am. Soc. Nephrol. 27, 1159-1173 (2016). [PubMed: 26311459]

53. Tsiokas L, Kim E, Arnould T, Sukhatme VP\& Walz, G. Homo- and heterodimeric interactions between the gene products of PKD1 and PKD2.Proc. Natl Acad. Sci. USA 94, 6965-6970 (1997). [PubMed: 9192675]

54. Shen PS et al. The structure of the polycystic kidney disease channel PKD2 in lipid nanodiscs. Cell 167, 763-773 (2016). [PubMed: 27768895]

55. Grieben $\mathrm{M}$ et al. Structure of the polycystic kidney disease TRP channel Polycystin-2 (PC2). Nat. Struct. Mol. Biol. 24, 114-122 (2017). [PubMed: 27991905] 
56. Qian F, Watnick TJ, Onuchic LF \& Germino GG The molecular basis of focal cyst formation in human autosomal dominant polycystic kidney disease type I. Cell 87, 979-987 (1996). [PubMed: 8978603]

57. Watnick T et al. Mutations of PKD1 in ADPKD2 cysts suggest a pathogenic effect of trans-h eterozygous mutations. Nat. Genet. 25, 143-144 (2000). [PubMed: 10835625]

58. Pei Y et al. Somatic PKD2 mutations in individual kidney and liver cysts support a 'two-hit' model of cystogenesis in type 2 autosomal dominant polycystic kidney disease. J. Am. Soc. Nephrol. 10, 1524-1529 (1999). [PubMed: 10405208]

59. Bergmann $\mathrm{C}$ et al. Mutations in multiple PKD genes may explain early and severe polycystic kidney disease. J. Am. Soc. Nephrol. 22, 2047-2056 (2011). [PubMed: 22034641]

60. Happe $\mathrm{H}$ et al. Toxic tubular injury in kidneys from Pkd1-deletion mice accelerates cystogenesis accompanied by dysregulated planar cell polarity and canonical Wnt signaling pathways. Hum. Mol. Genet. 18, 2532-2542 (2009). [PubMed: 19401297]

61. Patel V et al. Acute kidney injury and aberrant plana cell polarity induce cyst formation in mice lacking rena cilia. Hum. Mol. Genet. 17, 1578-1590 (2008). [PubMed: 18263895]

62. Lantinga-van Leeuwen IS et al. Lowering of Pkd1 expression is sufficient to cause polycystic kidney disease. Hum. Mol. Genet. 13, 3069-3077 (2004). [PubMed: 15496422]

63. Hopp K et al. Functional polycystin-1 dosage govern: autosomal dominant polycystic kidney disease severity. J. Clin. Invest. 122, 4257-4273 (2012). [PubMed: 23064367]

64. Cornec-Le Gall E et al. Type of PKD1 mutation influences renal outcome in ADPKD. J. Am. Soc. Nephrol. 24, 1006-1013 (2013). [PubMed: 23431072]

65. Leonhard WN et al. Scattered deletion of PKD1 in kidneys causes a cystic snowball effect and recapitulates polycystic kidney disease. J. Am. Soc. Nephrol. 26, 1322-1333 (2015). [PubMed: 25361818]

66. Heyer CM et al. Predicted mutation strength of nontruncating PKD1 mutations aids genotypephenotype correlations in autosomal dominant polycystic kidney disease. J. Am. Soc. Nephrol. 27, 2872-2884 (2016). [PubMed: 26823553]

67. Cornec-Le Gall E et al. The PROPKD score: a new algorithm to predict renal survival in autosomal dominant polycystic kidney disease. J. Am. Soc. Nephrol. 27, 942-951 (2016). [PubMed: 26150605]

68. Chebib FT et al. Effect of genotype on the severity and volume progression of polycystic liver disease in autosomal dominant polycystic kidney disease. Nephrol. Dial. Transplant. 31, 952-960 (2016). [PubMed: 26932689]

69. Irazabal MV et al. Extended follow-up of unrupture intracranial aneurysms detected by presymptomatic screening in patients with autosomal dominant polycystic kidney disease. Clin. J. Am. Soc. Nephrol. 6 1274-1285 (2011). [PubMed: 21551026]

70. Vujic $\mathrm{M}$ et al. Incompletely penetrant PKD1 alleles mimic the renal manifestations of ARPKD. J. Am. Soc Nephrol. 21, 1097-1102 (2010). [PubMed: 20558538]

71. Audrezet M-P et al. Comprehensive PKD1 and PKD mutation analysis in prenatal autosomal dominant polycystic kidney disease. J. Am. Soc. Nephrol. 27, 722-729 (2016). [PubMed: 26139440]

72. Losekoot $\mathrm{M}$ et al. Neonatal onset autosomal dominant polycystic kidney disease (ADPKD) in a patient homozygous for a PKD2 missense mutation due to uniparental disomy. J. Med. Genet. 49, 37-40 (2012). [PubMed: 22114106]

73. Pei $\mathrm{Y}$ et al. Bilineal disease and trans-heterozygotes in autosomal dominant polycystic kidney disease. Am J. Hum. Genet. 68, 355-363 (2001). [PubMed: 11156533]

74. Rossetti $\mathrm{S}$ et al. Mutation analysis of the entire PKD1 gene: genetic and diagnostic implications. Am. J. Hum Genet. 68, 46-63 (2001). [PubMed: 11115377]

75. Iliuta IA et al. Polycystic kidney disease without an apparent family history. J. Am. Soc. Nephrol. 28, 2768-2776 (2017). [PubMed: 28522688]

76. Persu A et al. Comparison between siblings and twins supports a role for modifier genes in ADPKD. Kidney Int. 66, 2132-2136 (2004). [PubMed: 15569302] 
77. Paterson $\mathrm{AD}$ et al. Progressive loss of renal function is an age-dependent heritable trait in type 1 autosomal dominant polycystic kidney disease. J. Am. Soc. Nephrol. 16, 755-762 (2005). [PubMed: 15677307]

78. Fain PR et al. Modifier genes play a significant role in the phenotypic expression of PKD1. Kidney Int. 67, 1256-1267 (2005). [PubMed: 15780078]

79. Liu X-G et al. Genetic variation of DKK3 may modify renal disease severity in PKD1. J. Am. Soc. Nephrol. 21, 1510-1520 (2010). [PubMed: 20616171]

80. Hogan MC et al. Characterization of PKD protein $\neg$ positive exosome-like vesicles. J. Am. Soc. Nephrol. 20, 278-288 (2009). [PubMed: 19158352]

81. Drummond IA Polycystins, focal adhesions and extracellular matrix interactions. Biochim. Biophys. Acta 1812, 1322-1326 (2011). [PubMed: 21396443]

82. Lee K, Battini L \& Gusella GL Cilium, centrosome and cell cycle regulation in polycystic kidney disease. Biochim. Biophys. Acta 1812, 1263-1271 (2011). [PubMed: 21376807]

83. Rowe I et al. Defective glucose metabolism in polycystic kidney disease identifies a new therapeutic strategy. Nat. Med. 19, 488-493 (2013). [PubMed: 23524344]

84. Yamaguchi T et al. Cyclic AMP activates B-Raf and ERK in cyst epithelial cells from autosomaldominant polycystic kidneys. Kidney Int. 63, 1983-1994 (2003). [PubMed: 12753285]

85. Fischer E et al. Defective planar cell polarity in polycystic kidney disease. Nat. Genet. 38, 21-23 (2006). [PubMed: 16341222]

86. Nauli SM et al. Polycystins 1 and 2 mediate mechanosensation in the primary cilium of kidney cells. Nat. Genet. 33, 129-137 (2003). [PubMed: 12514735]

87. Delling M, DeCaen PG, Doerner JF, Febvay S \& Clapham DE Primary cilia are specialized calcium signalling organelles. Nature 504, 311-314 (2013). [PubMed: 24336288]

88. Du J \& Wilson PD Abnormal polarization of EGF receptors and autocrine stimulation of cyst epithelial growth in human ADPKD. Am. J. Physiol. 269, C487-C495 (1995). [PubMed: 7653531]

89. MacRae Dell K, Nemo R, Sweeney WE Jr. \& Avner ED EGF-related growth factors in the pathogenesis of murine ARPKD. Kidney Int. 65, 2018-2029 (2004). [PubMed: 15149315]

90. Arnould $\mathrm{T}$ et al. The polycystic kidney disease 1 gene product mediates protein kinase $\mathrm{C}$ adependent and c-Jun N-terminal kinase-dependent activation of the transcription factor AP-1. J. Biol. Chem. 273, 6013-6018 (1998). [PubMed: 9497315]

91. Parnell SC et al. The polycystic kidney disease-1 protein, polycystin-1, binds and activates heterotrimeric G-proteins in vitro. Biochem. Biophys. Res. Commun. 251, 625-631 (1998). [PubMed: 9792824]

92. Bhunia AK et al. PKD1 induces p21(waf1) and regulation of the cell cycle via direct activation of the JAK-STAT signaling pathway in a process requiring PKD2. Cell 109, 157-168 (2002). [PubMed: 12007403]

93. Boca M et al. Polycystin-1 induces resistance to apoptosis through the phosphatidylinositol 3kinase/Akt signaling pathway. J. Am. Soc. Nephrol. 17, 637-647 (2006). [PubMed: 16452497]

94. Takiar V et al. Activating AMP-activated protein kinase (AMPK) slows renal cystogenesis. Proc. Natl Acad. Sci. USA 108, 2462-2467 (2011). [PubMed: 21262823]

95. Shillingford JM et al. The mTOR pathway is regulated by polycystin-1, and its inhibition reverses renal cystogenesis in polycystic kidney disease.Proc. Natl Acad. Sci. USA 103, 5466-5471 (2006). [PubMed: 16567633]

96. Renken C, Fischer D-C, Kundt G, Gretz N \& Haffner D Inhibition of mTOR with sirolimus does not attenuate progression of liver and kidney disease in PCK rats. Nephrol. Dial. Transplant. 26, 92-100 (2011). [PubMed: 20615907]

97. Leonhard WN et al. Curcumin inhibits cystogenesis by simultaneous interference of multiple signaling pathways: in vivo evidence from a Pkd1-deletion model. Am. J. Physiol. Renal Physiol. 300, F1193-F1202 (2011). [PubMed: 21345977]

98. Menezes LF et al. Network analysis of a Pkd1-mouse model of autosomal dominant polycystic kidney disease identifies HNF4alpha as a disease modifier. PLOS Genet. 8, e1003053 (2012). 
99. Chiaravalli M et al. 2-deoxy-d-glucose ameliorates PKD progression. J. Am. Soc. Nephrol. 27, 1958-1969 (2016). [PubMed: 26534924]

100. Riwanto $\mathrm{M}$ et al. Inhibition of aerobic glycolysis attenuates disease progression in polycystic kidney disease. PLOS ONE 11, e0146654 (2016).

101. Rodriguez D et al. Inhibition of sodium-glucose cotransporter 2 with dapagliflozin in han: SPRD rats with polycystic kidney disease. Kidney Blood Press Res. 40, 638-647 (2015). [PubMed: 26698317]

102. Menezes LF, Lin CC, Zhou F \& Germino GG Fatty acid oxidation is impaired in an orthologous mouse model of autosomal dominant polycystic kidney disease. EBioMedicine 5, 183-192 (2016). [PubMed: 27077126]

103. Ma M, Tian X, Igarashi P, Pazour GJ \& Somlo S Loss of cilia suppresses cyst growth in genetic models of autosomal dominant polycystic kidney disease. Nat. Genet. 45, 1004-1012 (2013). [PubMed: 23892607]

104. Lee K, Boctor S, Barisoni LMC \& Gusella GL Inactivation of integrin-beta1 prevents the development of polycystic kidney disease after the loss of polycystin-1. J. Am. Soc. Nephrol. 26, 888-895 (2015). [PubMed: 25145933]

105. Wilson PD, Geng L, Li X \& Burrow CR The PKD1 gene product, 'polycystin-1,' is a tyrosinephosphorylated protein that colocalizes with alpha2beta1-integrin in focal clusters in adherent renal epithelia. Lab Invest. 79, 1311-1323 (1999). [PubMed: 10532593]

106. Silberberg M, Charron AJ, Bacallao R \& Wandinger-Ness A Mispolarization of desmosomal proteins and altered intercellular adhesion in autosomal dominant polycystic kidney disease.Am. J. Physiol. Ren. Physiol. 288, F1153-F1163 (2005).

107. Castelli M et al. Regulation of the microtubular cytoskeleton by Polycystin-1 favors focal adhesions turnover to modulate cell adhesion and migration. BMC Cell Biol. 16, 15 (2015). [PubMed: 25947155]

108. Luyten A et al. Aberrant regulation of planar cell polarity in polycystic kidney disease. J. Am. Soc. Nephrol. 21, 1521-1532 (2010). [PubMed: 20705705]

109. Kunimoto $\mathrm{K}$ et al. Disruption of core planar cell polarity signaling regulates renal tubule morphogenesis but is not cystogenic. Curr. Biol. 27, 3120-3131 (2017). [PubMed: 29033332]

110. Griffin MD, Torres VE, Grande JP \& Kumar R Vascular expression of polycystin. J. Am. Soc. Nephrol. 8, 616-626 (1997). [PubMed: 10495791]

111. Huang JL et al. Vascular endothelial growth factor C for polycystic kidney diseases. J. Am. Soc. Nephrol. 27, 69-77 (2016). [PubMed: 26038530]

112. Outeda $P$ et al. Polycystin signaling is required for directed endothelial cell migration and lymphatic development. Cell Rep. 7, 634-644 (2014). [PubMed: 24767998]

113. Grantham JJ, Geiser JL \& Evan AP Cyst formation and growth in autosomal dominant polycystic kidney disease. Kidney Int. 31, 1145-1152 (1987). [PubMed: 3599654]

114. Liu D et al. A Pkd1-Fbn1 genetic interaction implicates TGF-beta signaling in the pathogenesis of vascular complications in autosomal dominant polycystic kidney disease. J. Am. Soc. Nephrol. 25, 81-91 (2014). [PubMed: 24071006]

115. Grantham JJ Clinical practice. Autosomal dominant polycystic kidney disease. N. Engl. J. Med. 359, 1477-1485 (2008). [PubMed: 18832246]

116. Swenson-Fields KI et al. Macrophages promote polycystic kidney disease progression. Kidney Int. 83, 855-864 (2013). [PubMed: 23423256]

117. Ta MH, Harris DC \& Rangan GK Role of interstitial inflammation in the pathogenesis of polycystic kidney disease. Nephrology (Carlton). 18, 317-330 (2013). [PubMed: 23448509]

118. Karihaloo A et al. Macrophages promote cyst growth in polycystic kidney disease. J. Am. Soc. Nephrol. 22, 1809-1814 (2011). [PubMed: 21921140]

119. Chen $\mathrm{L}$ et al. Macrophage migration inhibitory factor promotes cyst growth in polycystic kidney disease.J. Clin. Invest. 125, 2399-2412 (2015). [PubMed: 25961459]

120. Watnick TJ et al. Somatic mutation in individual liver cysts supports a two-hit model of cystogenesis in autosomal dominant polycystic kidney disease. Mol. Cell 2, 247-251 (1998). [PubMed: 9734362] 
121. Fedeles SV et al. A genetic interaction network of five genes for human polycystic kidney and liver diseases defines polycystin-1 as the central determinant of cyst formation. Nat. Genet. 43, 639-647 (2011). [PubMed: 21685914]

122. Ecder T \& Schrier RW Cardiovascular abnormalities in autosomal-dominant polycystic kidney disease. Nat. Rev. Nephrol. 5, 221-228 (2009). [PubMed: 19322187]

123. Belz MM et al. Familial clustering of ruptured intracranial aneurysms in autosomal dominant polycystic kidney disease. Am. J. Kidney Dis. 38, 770-776 (2001). [PubMed: 11576880]

124. Lorthioir A et al. Polycystin deficiency induces dopamine-reversible alterations in flow-mediated dilatation and vascular nitric oxide release in humans. Kidney Int. 87, 465-472 (2015). [PubMed: 25029430]

125. Sharif-Naeini R et al. Polycystin-1 and -2 dosage regulates pressure sensing. Cell 139, 587-596 (2009). [PubMed: 19879844]

126. Morel $\mathrm{N}$ et al. PKD1 haploinsufficiency is associated with altered vascular reactivity and abnormal calcium signaling in the mouse aorta. Pflugers Arch. 457, 845-856 (2009). [PubMed: 18679710]

127. Qian Q et al. Pkd2 haploinsufficiency alters intracellular calcium regulation in vascular smooth muscle cells. Hum. Mol. Genet. 12, 1875-1880 (2003). [PubMed: 12874107]

128. Hassane $\mathrm{S}$ et al. Pathogenic sequence for dissecting aneurysm formation in a hypomorphic polycystic kidney disease 1 mouse model. Arter. Thromb. Vasc. Biol. 27, 2177-2183 (2007).

129. Kim K, Drummond I, Ibraghimov-Beskrovnaya O, Klinger K \& Arnaout MA Polycystin 1 is required for the structural integrity of blood vessels. Proc. Natl Acad. Sci. USA 97, 1731-1736 (2000). [PubMed: 10677526]

130. Boulter $\mathrm{C}$ et al. Cardiovascular, skeletal, and renal defects in mice with a targeted disruption of the Pkd1 gene. Proc. Natl Acad. Sci. USA 98, 12174-12179 (2001). [PubMed: 11593033]

131. Pennekamp $P$ et al. The ion channel polycystin-2 is required for left-right axis determination in mice.Curr. Biol. 12, 938-943 (2002). [PubMed: 12062060]

132. Lu H et al. Mutations in DZIP1L, which encodes a ciliary-transition-zone protein, cause autosomal recessive polycystic kidney disease. Nat. Genet. 49, 1025-1034 (2017). [PubMed: 28530676]

133. Ahrabi AK et al. Glomerular and proximal tubule cysts as early manifestations of Pkd1 deletion. Nephrol. Dial. Transplant. 25, 1067-1078 (2010). [PubMed: 19945952]

134. Garcia-Gonzalez MA et al. Pkd1 and Pkd2 are required for normal placental development. PLOS ONE 5, e12821 (2010). [PubMed: 20862291]

135. Lu W et al. Perinatal lethality with kidney and pancreas defects in mice with a targeted Pkdl mutation. Nat. Genet. 17, 179-181 (1997). [PubMed: 9326937]

136. Lu W et al. Late onset of renal and hepatic cysts in Pkd1-targeted heterozygotes. Nat. Genet. 21, 160-161 (1999). [PubMed: 9988265]

137. Piontek $\mathrm{KB}$ et al. A functional floxed allele of $\mathrm{Pkd} 1$ that can be conditionally inactivated in vivo. J. Am. Soc. Nephrol. 15, 3035-3043 (2004). [PubMed: 15579506]

138. Lantinga-van Leeuwen IS et al. Kidney-specific inactivation of the Pkd1 gene induces rapid cyst formation in developing kidneys and a slow onset of disease in adult mice. Hum. Mol. Genet. 16, 3188-3196 (2007). [PubMed: 17932118]

139. Wu G et al. Somatic inactivation of Pkd2 results in polycystic kidney disease. Cell 93, 177-188 (1998). [PubMed: 9568711]

140. Bastos AP et al. Pkd1 haploinsufficiency increases renal damage and induces microcyst formation following ischemia/reperfusion. J. Am. Soc. Nephrol.20, 2389-2402 (2009). [PubMed: 19833899]

141. Bergmann C Genetics of autosomal recessive polycystic kidney disease and its differential diagnoses. Front. Pediatr. 10.3389/fped.2017.00221 (2018).

142. Onuchic LF et al. PKHD1, the polycystic kidney and hepatic disease 1 gene, encodes a novel large protein containing multiple immunoglobulin-like plexin-transcription-factor domains and parallel $\beta$-helix 1 repeats. Am. J. Hum. Genet. 70, 1305-1317 (2002). [PubMed: 11898128] 
143. Boddu R et al. Intragenic motifs regulate the transcriptional complexity of Pkhd1/PKHD1. J. Mol. Med. 92, 1045-1056 (2014). [PubMed: 24984783]

144. Ward CJ et al. The gene mutated in autosomal recessive polycystic kidney disease encodes a large, receptor-like protein. Nat. Genet. 30, 259-269 (2002). [PubMed: 11919560]

145. Ward CJ et al. Cellular and subcellular localization of the ARPKD protein; fibrocystin is expressed on primary cilia. Hum. Mol. Genet. 12, 2703-2710 (2003). [PubMed: 12925574]

146. Follit JA, Li L, Vucica Y \& Pazour GJThe cytoplasmic tail of fibrocystin contains a ciliary targeting sequence. J. Cell Biol. 188, 21-28 (2010). [PubMed: 20048263]

147. Hiesberger $\mathrm{T}$ et al. Proteolytic cleavage and nuclear translocation of fibrocystin is regulated by intracellular Ca2+ and activation of protein kinase C. J. Biol. Chem. 281, 34357-34364 (2006). [PubMed: 16956880]

148. Kaimori JY et al. Polyductin undergoes notch-like processing and regulated release from primary cilia. Hum. Mol. Genet. 16, 942-956 (2007). [PubMed: 17470460]

149. Cabezas OR et al. Polycystic kidney disease with hyperinsulinemic hypoglycemia caused by a promoter mutation in phosphomannomutase 2. J. Am. Soc. Nephrol. 28, 2529-2539 (2017). [PubMed: 28373276]

150. Bergmann $C$ et al. Spectrum of mutations in the gene for autosomal recessive polycystic kidney disease (ARPKD/PKHD1). J. Am. Soc. Nephrol. 14, 76-89 (2003). [PubMed: 12506140]

151. Menezes LFC et al. Polyductin, the PKHD1 gene product, comprises isoforms expressed in plasma membrane, primary cilium, and cytoplasm. Kidney Int. 66, 1345-1355 (2004). [PubMed: 15458427]

152. Zhang MZ et al. PKHD1 protein encoded by the gene for autosomal recessive polycystic kidney disease associates with basal bodies and primary cilia in renal epithelial cells. Proc. Natl Acad. Sci. USA 101, 2311-2316 (2004). [PubMed: 14983006]

153. Wang $\mathrm{S}$ et al. Fibrocystin/polyductin, found in the same protein complex with polycystin-2, regulates calcium responses in kidney epithelia. Mol. Cell. Biol. 27, 3241-3252 (2007). [PubMed: 17283055]

154. Fischer DC et al. Activation of the AKT/mTOR pathway in autosomal recessive polycystic kidney disease (ARPKD). Nephrol. Dial. Transplant. 24, 1819-1827 (2009). [PubMed: 19176689]

155. Garcia-Gonzalez MA et al. Genetic interaction studies link autosomal dominant and recessive polycystic kidney disease in a common pathway. Hum. Mol. Genet. 16, 1940-1950 (2007). [PubMed: 17575307]

156. Lager DJ, Qian Q, Bengal RJ, Ishibashi M \& Torres VE The pck rat: a new model that resembles human autosomal dominant polycystic kidney and liver disease. Kidney Int. 59, 126-136 (2001). [PubMed: 11135065]

157. O'Meara CC et al. Role of genetic modifiers in an orthologous rat model of ARPKD. Physiol. Genom. 44, 741-753 (2012).

158. Reeders ST et al. Prenatal diagnosis of autosomal dominant polycystic kidney disease with a DNA probe. Lancet 328, 6-8 (1986).

159. Grantham JJ et al. Volume progression in polycystic kidney disease. N. Engl. J. Med. 354, 21222130 (2006). [PubMed: 16707749]

160. Rule AD et al. Characteristics of renal cystic and solid lesions based on contrast-enhanced computed tomography of potential kidney donors. Am. J. Kidney Dis. 59, 611-618 (2012). [PubMed: 22398108]

161. Pei Y et al. Unified criteria for ultrasonographic diagnosis of ADPKD. J. Am. Soc. Nephrol. 20, 205-212 (2009). [PubMed: 18945943]

162. Belibi FA \& Edelstein CL Unified ultrasonographic diagnostic criteria for polycystic kidney disease. J. Am. Soc. Nephrol. 20, 6-8 (2009). [PubMed: 19073819]

163. Rossetti $\mathrm{S}$ et al. Comprehensive molecular diagnostics in autosomal dominant polycystic kidney disease. J. Am. Soc. Nephrol. 18, 2143-2160 (2007). [PubMed: 17582161]

164. Audrezet MP et al. Autosomal dominant polycystic kidney disease: comprehensive mutation analysis of PKD1 and PKD2 in 700 unrelated patients. Hum. Mutat. 33, 1239-1250 (2012). [PubMed: 22508176] 
165. Rossetti $\mathrm{S}$ et al. Identification of gene mutations in autosomal dominant polycystic kidney disease through targeted resequencing. J. Am. Soc. Nephrol. 23, 915-933 (2012). [PubMed: 22383692]

166. Trujillano D et al. Diagnosis of autosomal dominant polycystic kidney disease using efficient PKD1 and PKD2 targeted next-generation sequencing. Mol. Genet. Genom. Med. 2, 412-421 (2014).

167. Eisenberger $\mathrm{T}$ et al. An efficient and comprehensive strategy for genetic diagnostics of polycystic kidney disease. PLOS ONE 10, e0116680 (2015).

168. Mallawaarachchi AC et al. Whole-genome sequencing overcomes pseudogene homology to diagnose autosomal dominant polycystic kidney disease. Eur. J. Hum. Genet. 24, 1584-1590 (2016). [PubMed: 27165007]

169. Lanktree MB et al. Prevalence estimates of polycystic kidney and liver disease by population sequencing. J. Am. Soc. Nephrol. 29, 2593-2600 (2018). [PubMed: 30135240]

170. Rossetti S et al. Incompletely penetrant PKD1 alleles associated with mild, homozygous or in utero onset PKD. J. Am. Soc. Nephrol. 18, 848-855 (2009).

171. Consugar MB et al. Characterization of large rearrangements in autosomal dominant polycystic kidney disease and the PKD1/TSC2 contiguous gene syndrome. Kidney Int. 74, 1468-1479 (2008). [PubMed: 18818683]

172. Tan AY et al. Autosomal dominant polycystic kidney disease caused by somatic and germline mosaicism. Clin. Genet. 87, 373-377 (2015). [PubMed: 24641620]

173. Cnossen WR \& Drenth JP Polycystic liver disease: an overview of pathogenesis, clinical manifestations and management. Orphanet J. Rare Dis. 9, 69 (2014). [PubMed: 24886261]

174. Drenth JPH, Chrispijn M \& Bergmann C Congenital fibrocystic liver diseases. Best Pract. Res. Clin. Gastroenterol. 24, 573-584 (2010). [PubMed: 20955960]

175. De Rechter S et al. Clinicians' attitude towards family planning and timing of diagnosis in autosomal dominant polycystic kidney disease. PLOS ONE 12, e0185779 (2017).

176. Massella L et al. Prevalence of hypertension in children with early-stage ADPKD. Clin. J. Am. Soc. Nephrol. 13, 874-883 (2018).

177. Marlais $\mathrm{M}$ et al. Hypertension in autosomal dominant polycystic kidney disease: a meta-analysis. Arch. Dis. Child 101, 1142-1147 (2016). [PubMed: 27288429]

178. Irazabal MV et al. Imaging classification of autosomal dominant polycystic kidney disease: a simple model for selecting patients for clinical trials. J. Am. Soc. Nephrol. 26, 160-172 (2015). [PubMed: 24904092]

179. Gansevoort RT et al. Recommendations for the use of tolvaptan in autosomal dominant polycystic kidney disease: a position statement on behalf of the ERA-EDTA Working Groups on Inherited Kidney Disorders and European Renal Best Practice. Nephrol. Dial Transpl. 31, 337-348 (2016).

180. Gunay-Aygun $\mathrm{M}$ et al. Autosomal recessive polycystic kidney disease and congenital hepatic fibrosis: summary statement of a first National Institutes of Health/Office of Rare Diseases conference. J. Pediatr. 149, 159-164 (2006). [PubMed: 16887426]

181. Adeva $\mathrm{M}$ et al. Clinical and molecular characterization defines a broadened spectrum of autosomal recessive polycystic kidney disease (ARPKD). Medicine (Baltimore). 85, 1-21 (2006). [PubMed: 16523049]

182. Dell KM et al. Kidney disease progression in autosomal recessive polycystic kidney disease.J. Pediatr. 171, 196-201 (2016). [PubMed: 26831744]

183. Guay-Woodford LM et al. Consensus expert recommendations for the diagnosis and management of autosomal recessive polycystic kidney disease: report of an international conference. J. Pediatr. 165, 611-617 (2014). [PubMed: 25015577]

184. Fonck $\mathrm{C}$ et al. Autosomal recessive polycystic kidney disease in adulthood. Nephrol. Dial. Transplant. 16, 1648-1652 (2001). [PubMed: 11477168]

185. Avni FE et al. Hereditary polycystic kidney diseases in children: changing sonographic patterns through childhood. Pediatr. Radiol. 32, 169-174 (2002). [PubMed: 12164348]

186. Bergmann $\mathrm{C}$ et al. PKHD1 mutations in autosomal recessive polycystic kidney disease (ARPKD).Hum. Mutat. 23, 453-463 (2004). [PubMed: 15108277] 
187. Consugar MB et al. Haplotype analysis improves molecular diagnostics of autosomal recessive polycystic kidney disease. Am. J. Kidney Dis. 45, 77-87 (2005). [PubMed: 15696446]

188. Liu L, Li K, Fu X, Chung C \& Zhang KA Forward look at noninvasive prenatal testing. Trends Mol. Med. 22, 958-968 (2016). [PubMed: 27726956]

189. Chervenak FA \& McCullough LB Ethical issues in perinatal genetics. Semin. Fetal Neonatal Med. 16, 70-73 (2011). [PubMed: 21051301]

190. Chebib FT \& Torres VE Autosomal dominant polycystic kidney disease: core curriculum 2016. Am. J. Kidney Dis. 67, 792-810 (2016). [PubMed: 26530876]

191. Dhariwal M, Rasmussen M \& Holstein BE Body mass index and smoking: cross-sectional study of a representative sample of adolescents in Denmark. Int. J. Publ. Heal. 55, 307-314 (2010).

192. Ahrabi AK et al. PKD1 haploinsufficiency causes a syndrome of inappropriate antidiuresis in mice. J. Am. Soc. Nephrol. 18, 1740-1753 (2007). [PubMed: 17475819]

193. Boertien WE et al. Relationship of copeptin, a surrogate marker for arginine vasopressin, with change in total kidney volume and GFR decline in autosomal dominant polycystic kidney disease: results from the CRISP cohort. Am. J. Kidney Dis. 61, 420-429 (2013). [PubMed: 23089511]

194. Bankir L, Bouby N \& Ritz E Vasopressin: a novel target for the prevention and retardation of kidney disease? Nat. Rev. Nephrol. 9, 223-239 (2013). [PubMed: 23438973]

195. Torres VE et al. Potentially modifiable factors affecting the progression of autosomal dominant polycystic kidney disease. Clin. J. Am. Soc. Nephrol. 6, 640-647 (2011).

196. Nowak KL et al. Overweight and obesity are predictors of progression in early autosomal dominant polycystic kidney disease. J. Am. Soc. Nephrol. 29, 571-578 (2018). [PubMed: 29118087]

197. Torres VE et al. Tolvaptan in patients with autosomal dominant polycystic kidney disease. N. Engl. J. Med. 367, 2407-2418 (2012). [PubMed: 23121377]

198. Torres VE et al. Tolvaptan in later-stage autosomal dominant polycystic kidney disease. N. Engl. J. Med. 377, 1930-1942 (2017). [PubMed: 29105594]

199. Chebib FT et al. A practical guide for treatment of rapidly progressive ADPKD with tolvaptan. J. Am. Soc. Nephrol. 29, 2458-2470 (2018). [PubMed: 30228150]

200. Caroli A et al. Effect of longacting somatostatin analogue on kidney and cyst growth in autosomal dominant polycystic kidney disease (ALADIN): a randomised, placebo-controlled, multicentre trial. Lancet 382, 1485-1495 (2013). [PubMed: 23972263]

201. Serra AL et al. Sirolimus and kidney growth in autosomal dominant polycystic kidney disease. N. Engl. J. Med. 363, 820-829 (2010). [PubMed: 20581391]

202. Perico N et al. Sirolimus therapy to halt the progression of ADPKD. J. Am. Soc. Nephrol. 21, 1031-1040 (2010). [PubMed: 20466742]

203. Walz $\mathrm{G}$ et al. Everolimus in patients with autosomal dominant polycystic kidney disease. N. Engl. J. Med. 363, 830-840 (2010). [PubMed: 20581392]

204. Cadnapaphornchai MA et al. Effect of pravastatin on total kidney volume, left ventricular mass index, and microalbuminuria in pediatric autosomal dominant polycystic kidney disease. Clin. J. Am. Soc. Nephrol. 9, 889-896 (2014). [PubMed: 24721893]

205. Schrier RS et al. Blood pressure in early autosomal dominant polycystic kidney disease. N. Engl. J. Med. 371, 2255-2266 (2014). [PubMed: 25399733]

206. Irazabal MV et al. Prognostic enrichment design in clinical trials for ADPKD: the HALT PKD clinical trial. Nephrol. Dial. Transplant. 32, 1857-1865 (2017). [PubMed: 27484667]

207. Torres VE et al. Angiotensin blockade in late autosomal dominant polycystic kidney disease. N. Engl. J. Med. 371, 2267-2276 (2014). [PubMed: 25399731]

208. Tellman MW, Bahler CD, Shumate AM, Bacallao RL \& Sundaram CP Management of pain in autosomal dominant polycystic kidney disease and anatomy of renal innervation. J. Urol. 193, 1470-1478 (2015). [PubMed: 25534330]

209. Casteleijn NF et al. A stepwise approach for effective management of chronic pain in autosomaldominant polycystic kidney disease. Nephrol. Dial. Transplant. 29(Suppl. 4), iv142-iv153 (2014). [PubMed: 25165181] 
210. de Jager RL et al. Catheter-based renal denervation as therapy for chronic severe kidney-related pain. Nephrol. Dial. Transplant. 33, 614-619 (2017).

211. Hulme P \& Wylie K Towards evidence based emergency medicine: best BETs from the Manchester Royal Infirmary. BET 1: tranexamic acid in life-threatening haematuria. Emerg. Med. J. 32, 168-169 (2015). [PubMed: 25605262]

212. Mallett A, Patel M, Tunnicliffe DJ \& Rangan GK KHA-CARI autosomal dominant polycystic kidney disease guideline: management of renal stone disease. Semin. Nephrol. 35, 603-606 (2015). [PubMed: 26718165]

213. Yili L et al. Flexible ureteroscopy and holmium laser lithotripsy for treatment of upper urinary tract calculi in patients with autosomal dominant polycystic kidney disease. Urol. Res. 40, 87-91 (2012). [PubMed: 21611814]

214. Jouret F et al. Diagnosis of cyst infection in patients with autosomal dominant polycystic kidney disease: attributes and limitations of the current modalities. Nephrol. Dial. Transplant. 27, 37463751 (2012). [PubMed: 23114901]

215. Lantinga MA, Drenth JP \& Gevers TJ Diagnostic criteria in renal and hepatic cyst infection. Nephrol. Dial. Transplant. 30, 744-751 (2014). [PubMed: 24950937]

216. Neuville M, Hustinx R, Jacques J, Krzesinski JM \& Jouret F Diagnostic algorithm in the management of acute febrile abdomen in patients with autosomal dominant polycystic kidney disease. PLOS ONE 11, e0161277 (2016).

217. Lantinga MA et al. Management of renal cyst infection in patients with autosomal dominant polycystic kidney disease: a systematic review. Nephrol. Dial. Transplant. 32, 144-150 (2017). [PubMed: 26908766]

218. Watanabe $\mathrm{K}$ et al. A case of autosomal dominant polycystic kidney disease with emphysematous polycystic renal infection that required surgical treatment. Intern. Med. 10.2169/ internalmedicine.1257-18 (2018).

219. Karami S et al. Risk of renal cell carcinoma among kidney transplant recipients in the United States. Am. J. Transplant. 16, 3479-3489 (2016). [PubMed: 27160653]

220. Keith DS, Torres VE, King BF, Zincki H \& Farrow GM Renal cell carcinoma in autosomal dominant polycystic kidney disease. J. Am. Soc. Nephrol. 4, 1661-1669 (1994). [PubMed: 8011975]

221. Xu L et al. Percutaneous radiofrequency ablation with contrast-enhanced ultrasonography for solitary and sporadic renal cell carcinoma in patients with autosomal dominant polycystic kidney disease. World J. Surg. Oncol. 14, 193 (2016). [PubMed: 27460786]

222. Spithoven EM et al. Renal replacement therapy for autosomal dominant polycystic kidney disease (ADPKD) in Europe: prevalence and survival-an analysis of data from the ERA-EDTA Registry. Nephrol. Dial. Transplant. 29, 15-25 (2014). [PubMed: 23986077]

223. Jung $Y$ et al. Volume regression of native polycystic kidneys after renal transplantation. Nephrol. Dial. Transplant. 31, 73-79 (2015). [PubMed: 26044834]

224. Neeff HP et al. One hundred consecutive kidney transplantations with simultaneous ipsilateral nephrectomy in patients with autosomal dominant polycystic kidney disease. Nephrol. Dial. Transplant. 28, 466-471 (2013). [PubMed: 23042709]

225. Courivaud $\mathrm{C}$ et al. Polycystic kidney size and outcomes on peritoneal dialysis: comparison with haemodialysis. Clin. Kidney J. 7, 138-143 (2014). [PubMed: 25852862]

226. Perrone RD, Ruthazer R \& Terrin NC Survival after end-stage renal disease in autosomal dominant polycystic kidney disease: contribution of extrarenal complications to mortality. Am. J. Kidney Dis. 38, 777-784 (2001). [PubMed: 11576881]

227. Hogan MC et al. Liver involvement in early autosomal-dominant polycystic kidney disease.Clin. Gastroenterol. Hepatol. 13, 155-164 (2015). [PubMed: 25111236]

228. Drenth JP, Chrispijn M, Nagorney DM, Kamath PS \& Torres VE Medical and surgical treatment options for polycystic liver disease. Hepatology 52, 2223-2230 (2010). [PubMed: 21105111]

229. Chebib FT et al. Outcomes and durability of hepatic reduction after combined partial hepatectomy and cyst fenestration for massive polycystic liver disease. J. Am. Coll. Surg. 223, 118-126 (2016). [PubMed: 27016902] 
230. Hoshino J et al. Intravascular embolization therapy in patients with enlarged polycystic liver. Am. J. Kidney Dis. 63, 937-944 (2014). [PubMed: 24602778]

231. Yang J et al. Comparison of volume-reductive therapies for massive polycystic liver disease in autosomal dominant polycystic kidney disease. Hepatol. Res. 46, 183-191 (2016). [PubMed: 26190457]

232. van Keimpema L, de Man RA \& Drenth JP Somatostatin analogues reduce liver volume in polycystic liver disease. Gut 57, 1338-1339 (2008). [PubMed: 18719151]

233. Caroli A et al. Reducing polycystic liver volume in ADPKD: effects of somatostatin analogue octreotide. Clin. J. Am. Soc. Nephrol. 5, 783-789 (2010). [PubMed: 20185596]

234. Hogan MC et al. Randomized clinical trial of long-acting somatostatin for autosomal dominant polycystic kidney and liver disease. J. Am. Soc. Nephrol. 21, 1052-1061 (2010). [PubMed: 20431041]

235. Hogan MC et al. Efficacy of 4 years of octreotide long-acting release therapy in patients with severe polycystic liver disease. Mayo Clin. Proc. 90, 1030-1037 (2015). [PubMed: 26166166]

236. Gevers TJ et al. Young women with polycystic liver disease respond best to somatostatin analogues: a pooled analysis of individual patient data. Gastroenterology 145, 352-357 (2013).

237. Ishikawa I et al. High incidence of common bile duct dilatation in autosomal dominant polycystic kidney disease patients. Am. J. Kidney Dis. 27, 321-326 (1996). [PubMed: 8604699]

238. Pirson Y, Chauveau D \& Torres V Management of cerebral aneurysms in autosomal dominant polycystic kidney disease. J. Am. Soc. Nephrol. 13, 269-276 (2002). [PubMed: 11752048]

239. Brown RD \& Torner J Unruptured intracranial aneurysms: some questions answered, many questions remain. Re: Pelz D. CURES and the dilemma of unruptured intracranial aneurysms. Can J Neuro Sci. 2011 Mar;38(2):191-2. Can. J. Neurol. Sci. 38, 785-787 (2011).

240. Rozenfeld MN et al. Autosomal dominant polycystic kidney disease and intracranial aneurysms: is there an increased risk of treatment? AJNR Am. J. Neuroradiol 37, 290-293 (2016). [PubMed: 26338918]

241. Flahault A et al. Screening for intracranial aneurysms in autosomal dominant polycystic kidney disease is cost-effective. Kidney Int. 93, 716-726 (2018). [PubMed: 29061331]

242. Jiang $\mathrm{T}$ et al. A follow-up study of autosomal dominant polycystic kidney disease with intracranial aneurysms using 3.0 T three-dimensional time-of-flight magnetic resonance angiography. Eur. J. Radiol 82, 1840-1845 (2013). [PubMed: 23466029]

243. Ring T \& Spiegelhalter D Risk of intracranial aneurysm bleeding in autosomal-dominant polycystic kidney disease. Kidney Int. 72, 1400-1402 (2007). [PubMed: 17882153]

244. Xu HW, Yu SQ, Mei CL \& Li MH Screening for intracranial aneurysm in 355 patients with autosomal-dominant polycystic kidney disease. Stroke 42, 204-206 (2011). [PubMed: 21164130]

245. Flahault A et al. Screening for unruptured intracranial aneurysms in autosomal dominant polycystic kidney disease: a survey of 420 nephrologists. PLOS ONE 11, e0153176 (2016).

246. Hartung EA \& Guay-Woodford LM Autosomal recessive polycystic kidney disease: a hepatorenal fibrocystic disorder with pleiotropic effects. Pediatrics 134, e833-e845 (2014). [PubMed: 25113295]

247. Lilova M, Kaplan BS \& Meyers KEC Recombinant human growth hormone therapy in autosomal recessive polycystic kidney disease. Pediatr. Nephrol. 18, 57-61 (2003). [PubMed: 12488992]

248. Becker T et al. Paediatric kidney transplantation in small children- a single centre experience. Transpl. Int. 19, 197-202 (2006). [PubMed: 16441768]

249. Davis ID, Ho M, Hupertz V \& Avner ED Survival of childhood polycystic kidney disease following renal transplantation: the impact of advanced hepatobiliary disease. Pediatr. Transplant. 7, 364-369 (2003). [PubMed: 14738296]

250. Srinath A \& Shneider BL Congenital hepatic fibrosis and autosomal recessive polycystic kidney disease. J. Pediatr. Gastroenterol. Nutr. 54, 580-587 (2012). [PubMed: 22197937]

251. Chapal $\mathrm{M}$ et al. Kidney and liver transplantation in patients with autosomal recessive polycystic kidney disease: a multicentric study. Nephrol. Dial. Transplant. 27, 2083-2088 (2012). [PubMed: 22076432] 
252. Telega G, Cronin D \& Avner ED New approaches to the autosomal recessive polycystic kidney disease patient with dual kidney-liver complications. Pediatr. Transplant. 17, 328-335 (2013). [PubMed: 23593929]

253. Brinkert $\mathrm{F}$ et al. Combined liver-kidney transplantation for children with autosomal recessive polycystic kidney disease (ARPKD): indication and outcome. Transpl. Int. 26, 640-650 (2013). [PubMed: 23582048]

254. Patrick DL \& Erickson P Health Status and Health Policy: Quality of Life in Health Care Evaluation and Resource Allocation (Oxford Univ. Press Inc., 1993).

255. Eriksson D et al. Health-related quality of life across all stages of autosomal dominant polycystic kidney disease. Nephrol. Dial. Transplant. 32, 2106-2111 (2017). [PubMed: 27662885]

256. Miskulin DC et al. Health-related quality of life in patients with autosomal dominant polycystic kidney disease and CKD stages 1-4: a cross-sectional study. Am. J. Kidney Dis. 63, 214-226 (2014). [PubMed: 24183837]

257. Simms RJ, Thong KM, Dworschak GC \& Ong AC Increased psychosocial risk, depression and reduced quality of life living with autosomal dominant polycystic kidney disease. Nephrol. Dial. Transplant. 31, 1130-1140 (2016). [PubMed: 26268712]

258. Mujais SK et al. Health-related quality of life in CKD patients: correlates and evolution over time. Clin. J. Am. Soc. Nephrol. 4, 1293-1301 (2009).

259. Rizk D et al. Quality of life in autosomal dominant polycystic kidney disease patients not yet on dialysis. Clin. J. Am. Soc. Nephrol. 4, 560-566 (2009).

260. Oberdhan D et al. Development of the autosomal dominant polycystic kidney disease impact scale: a new health-related quality-of-life instrument. Am. J. Kidney Dis. 71, 225-235 (2018). [PubMed: 29150246]

261. Tong A et al. A painful inheritance-patient perspectives on living with polycystic kidney disease: thematic synthesis of qualitative research. Nephrol. Dial. Transplant. 30, 790-800 (2015). [PubMed: 25637642]

262. Gainullin VG, Hopp K, Ward CJ, Hommerding CJ \& Harris PC Polycystin-1 maturation requires polycystin-2 in a dose-dependent manner. J. Clin. Invest. 125, 607-620 (2015). [PubMed: 25574838]

263. Kim H et al. Ciliary membrane proteins traffic through the Golgi via a Rabep1/GGA1/Arl3dependent mechanism. Nat. Commun. 5, 5482 (2014). [PubMed: 25405894]

264. Tan AY et al. Somatic mutations in renal cyst epithelium in autosomal dominant polycystic kidney disease. J. Am. Soc. Nephrol. 29, 2139-2156 (2018). [PubMed: 30042192]

265. Lin F et al. Kidney-specific inactivation of the KIF3A subunit of kinesin-II inhibits renal ciliogenesis and produces polycystic kidney disease. Proc. Natl Acad. Sci. USA 100, 5286-5291 (2003). [PubMed: 12672950]

266. Garcia-Gonzalo FR et al. A transition zone complex regulates mammalian ciliogenesis and ciliary membrane composition. Nat. Gen. 43, 776-784 (2011).

267. Chih B et al. A ciliopathy complex at the transition zone protects the cilia as a privileged membrane domain. Nat. Cell Biol. 14, 61-72 (2012).

268. Kim S et al. The polycystin complex mediates Wnt/Ca2+ signalling. Nat. Cell Biol. 18, 752-764 (2016). [PubMed: 27214281]

269. DeCaen PG, Delling M, Vien TN \& Clapham DE Direct recording and molecular identification of the calcium channel of primary cilia. Nature 504, 315-318 (2013). [PubMed: 24336289]

270. Mick DU et al. Proteomics of primary cilia by proximity labeling. Dev. Cell 35, 497-512 (2015). [PubMed: 26585297]

271. Yuan S, Zhao L, Brueckner M \& Sun Z Intraciliary calcium oscillations initiate vertebrate leftright asymmetry. Curr. Biol. 25, 556-567 (2015). [PubMed: 25660539]

272. Moser $\mathrm{M}$ et al. A mouse model for cystic biliary dysgenesis in autosomal recessive polycystic kidney disease (ARPKD). Hepatology 41, 1113-1121 (2005). [PubMed: 15830394]

273. Bakeberg JL et al. Epitope-tagged Pkhd1 tracks the processing, secretion, and localization of fibrocystin.J. Am. Soc. Nephrol. 22, 2266-2277 (2011). [PubMed: 22021705] 
274. Galarreta CI et al. Tubular obstruction leads to progressive proximal tubular injury and atubular glomeruli in polycystic kidney disease. Am. J. Pathol. 184, 1957-1966 (2014). [PubMed: 24815352]

275. Wood CR \& Rosenbaum JL Ciliary ectosomes: transmissions from the cell's antenna. Trends Cell Biol. 25, 276-285 (2015). [PubMed: 25618328]

276. Chauvet V et al. Mechanical stimuli induce cleavage and nuclear translocation of the polycystin-1 C terminus. J. Clin. Invest. 114, 1433-1443 (2004). [PubMed: 15545994]

277. Tran PV et al. Downregulating hedgehog signaling reduces renal cystogenic potential of mouse models. J. Am. Soc. Nephrol. 25, 2201-2212 (2014). [PubMed: 24700869]

278. Kline TL et al. Image texture features predict renal function decline in patients with autosomal dominant polycystic kidney disease. Kidney Int. 92, 1206-1216 (2017). [PubMed: 28532709]

279. Hogan MC et al. Identification of biomarkers for PKD1 using urinary exosomes. J. Am. Soc. Nephrol. 26, 1661-1670 (2015). [PubMed: 25475747]

280. Pejchinovski M et al. Urine peptidome analysis predicts risk of end-stage renal disease and reveals proteolytic pathways involved in autosomal dominant polycystic kidney disease progression. Nephrol. Dial. Transplant. 32, 487-497 (2016).

281. Shillingford JM, Leamon CP, Vlahov IR \& Weimbs T Folate-conjugated rapamycin slows progression of polycystic kidney disease. J. Am. Soc. Nephrol. 23, 1674-1681 (2012). [PubMed: 22859856]

282. Warner $\mathrm{G}$ et al. Food restriction ameliorates the development of polycystic kidney disease. J. Am. Soc. Nephrol. 27, 1437-1447 (2015). [PubMed: 26538633]

283. Hopp K et al. Tolvaptan plus pasireotide shows enhanced efficacy in a PKD1 model. J. Am. Soc. Nephrol. 26, 39-47 (2014). [PubMed: 24994926]

284. Masyuk TV, Masyuk AI \& La Russo NF Therapeutic targets in polycystic liver disease. Curr. Drug Targets 18, 950-957 (2015).

285. Wainwright CE et al. Lumacaftor-ivacaftor in patients with cystic fibrosis homozygous for Phe508del CFTR. N. Engl. J. Med. 373, 220-231 (2015). [PubMed: 25981758]

286. Nelson CE et al. In vivo genome editing improves muscle function in a mouse model of Duchenne muscular dystrophy. Science 351, 403-407 (2016). [PubMed: 26721684]

287. Tabebordbar $\mathrm{M}$ et al. In vivo gene editing in dystrophic mouse muscle and muscle stem cells. Science 351, 407-411 (2016). [PubMed: 26721686]

288. Fedeles SV et al. Sec63 and Xbp1 regulate IRE1a activity and polycystic disease severity. J. Clin. Invest. 125, 1955-1967 (2015). [PubMed: 25844898]

289. Nagel-Wolfrum K, Moller F, Penner I, Baasov T\& Wolfrum U Targeting nonsense mutations in diseases with translational read-through-inducing drugs (TRIDs). BioDrugs 30, 49-74 (2016). [PubMed: 26886021]

290. Wojtal D et al. Spell checking nature: versatility of CRISPR/Cas9 for developing treatments for inherited disorders. Am. J. Hum. Genet. 98, 90-101 (2016). [PubMed: 26686765]

291. Huang E et al. DNA testing for live kidney donors at risk for autosomal dominant polycystic kidney disease. Transplantation 87, 133-137 (2009). [PubMed: 19136903]

292. Harris PC \& Rossetti S Molecular diagnostics for autosomal dominant polycystic kidney disease. Nat. Rev. Nephrol. 6, 197-206 (2010). [PubMed: 20177400]

293. Chebib FT, Sussman CR, Wang X, Harris PC \& Torres VE Vasopressin and disruption of calcium signalling in polycystic kidney disease. Nat. Rev. Nephrol. 11, 451-464 (2015). [PubMed: 25870007]

294. Ong ACM \& Harris PC A polycystin-centric view of cyst formation and disease: the polycystins revisited. Kidney Int. 88, 699-710 (2015). [PubMed: 26200945]

295. Streets AJ, Wessely O, Peters DJ \& Ong AC Hyperphosphorylation of polycystin-2 at a critical residue in disease reveals an essential role for polycystin-1-regulated dephosphorylation. Hum. Mol. Genet. 22, 1924-1939 (2013). [PubMed: 23390129]

296. Kim I et al. Fibrocystin/polyductin modulates renal tubular formation by regulating polycystin-2 expression and function. J. Am. Soc. Nephrol. 19, 455-468 (2008). [PubMed: 18235088] 
297. Koulen P et al. Polycystin-2 is an intracellular calcium release channel. Nat. Cell Biol. 4, 191-197 (2002). [PubMed: 11854751]

298. Hartung EA \& Guay-Woodford LM Polycystic kidney disease: DZIP1L defines a new functional zip code for autosomal recessive PKD. Nat. Rev. Nephrol. 13, 519-520 (2017). [PubMed: 28736432]

299. Song CJ, Zimmerman KA, Henke SJ \& Yoder BK Inflammation and fibrosis in polycystic kidney disease. Results Probl. Cell Differ. 60, 323-344 (2017).

300. Qian Q, Harris PC \& Torres VE Treatment prospects for autosomal-dominant polycystic kidney disease. Kidney Int. 59, 2005-2022 (2001). [PubMed: 11380803]

301. Brancatelli $\mathrm{G}$ et al. Fibropolycystic liver disease: CT and MR imaging findings. RadioGraphics 25, 659-670 (2005). [PubMed: 15888616]

302. Ho TA et al. Autosomal dominant polycystic kidney disease is associated with central and nephrogenic defects in osmoregulation. Kidney Int. 82, 1121-1129 (2012). [PubMed: 22718190]

303. O'Brien $\mathrm{K}$ et al. Congenital hepatic fibrosis and portal hypertension in autosomal dominant polycystic kidney disease. J. Pediatr. Gastroenterol. Nutr. 54, 83-89 (2012). [PubMed: 21694639]

304. Luciano RL \& Dahl NK Extra-renal manifestations of autosomal dominant polycystic kidney disease (ADPKD): considerations for routine screening and management. Nephrol. Dial. Transplant. 29, 247-254 (2014). [PubMed: 24215018] 


\section{Box 1 |}

\section{Indications for genetic testing in ADPKD}

- In a young relative who is a potential kidney donor for a patient with autosomal dominant polycystic kidney disease (ADPKD), especially if one or two cysts are detected by imaging methods - to exclude genetically affected relatives ${ }^{291}$.

- In individuals with a negative family history - to establish a firm diagnosis or to test for mosaicism ${ }^{74}$ (note that at least $10-15 \%$ of families with ADPKD can be traced to a new (de novo) mutation).

- In cases of polycystic kidney disease of unknown origin and a negative family history — to assess recurrence risk and for family planning ${ }^{47}$.

- In patients with very early-onset disease — to identify biallelic disease or other complex genetics ${ }^{59,248,292}$.

- In patients with mild disease - to establish whether the disease is genetic and its cause ${ }^{292}$.

- In patients who are starting treatment or are being considered for a clinical trial - to establish a firm diagnosis and help determine whether the disease is rapidly progressive.

- In all patients with ADPKD - if treatment is fairly inexpensive and reliable, most patients can obtain a firm diagnosis and prognostic information. 
a
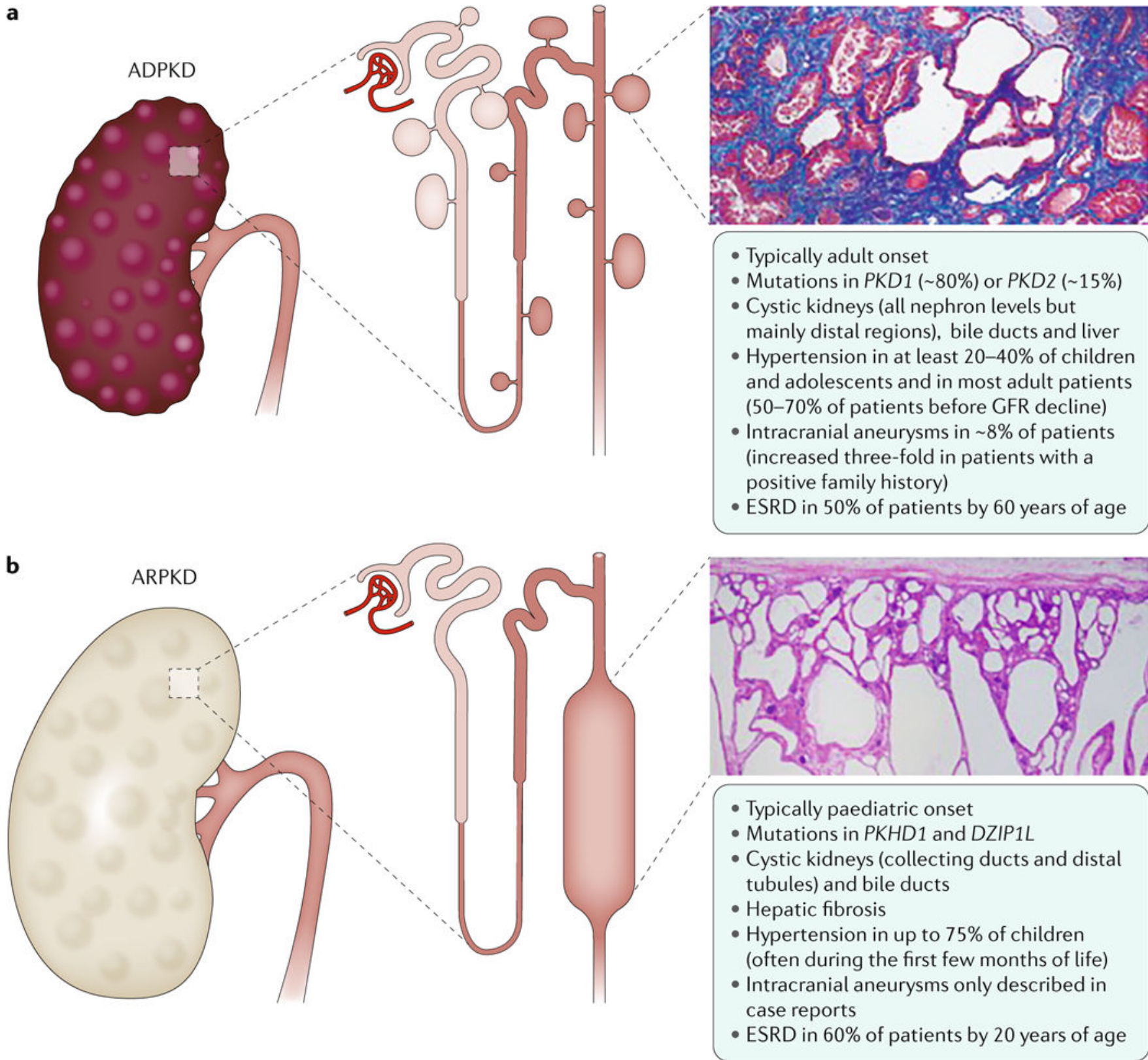

Fig. 1 |. Renal and extrarenal manifestations in polycystic kidney disease.

a Autosomal dominant polycystic kidney disease (ADPKD) is the most common form of polycystic kidney disease (PKD) and is mainly caused by mutations in PKD1 and PKD2, which encode polycystin 1 and polycystin 2, respectively. ADPKD is usually an adult-onset disease that is characterized by the formation of fluid-filled cysts in various locations in the kidneys, but mostly in the distal regions. The histology image is of the kidney (stained with Malloy trichrome stain) of a 49-year-old patient with end-stage ADPKD. Small cysts and extensive fibrosis (blue) are visible. $\mathbf{b} \mid$ Autosomal recessive PKD (ARPKD) is rarer and more severe than ADPKD and is caused by mutations in polycystic kidney and hepatic disease 1 (PKHD1; which encodes fibrocystin) and DZIP1L (which encodes DAZinteracting protein 1-like protein (DZIP1L)). ARPKD usually presents in utero, perinatally 
or in infancy and is characterized by the formation of cysts from the renal distal tubules and collecting ducts. Microscopically, cysts are fusiform dilatations of the aforementioned distal parts of the nephron, which are lined by a columnar or cuboidal epithelium. Respective dilated collecting ducts run perpendicular to the renal capsule (renal section is stained with haematoxylin and eosin). Both diseases often progress to end-stage renal disease (ESRD) that requires renal replacement therapy. GFR,glomerular filtration rate. 


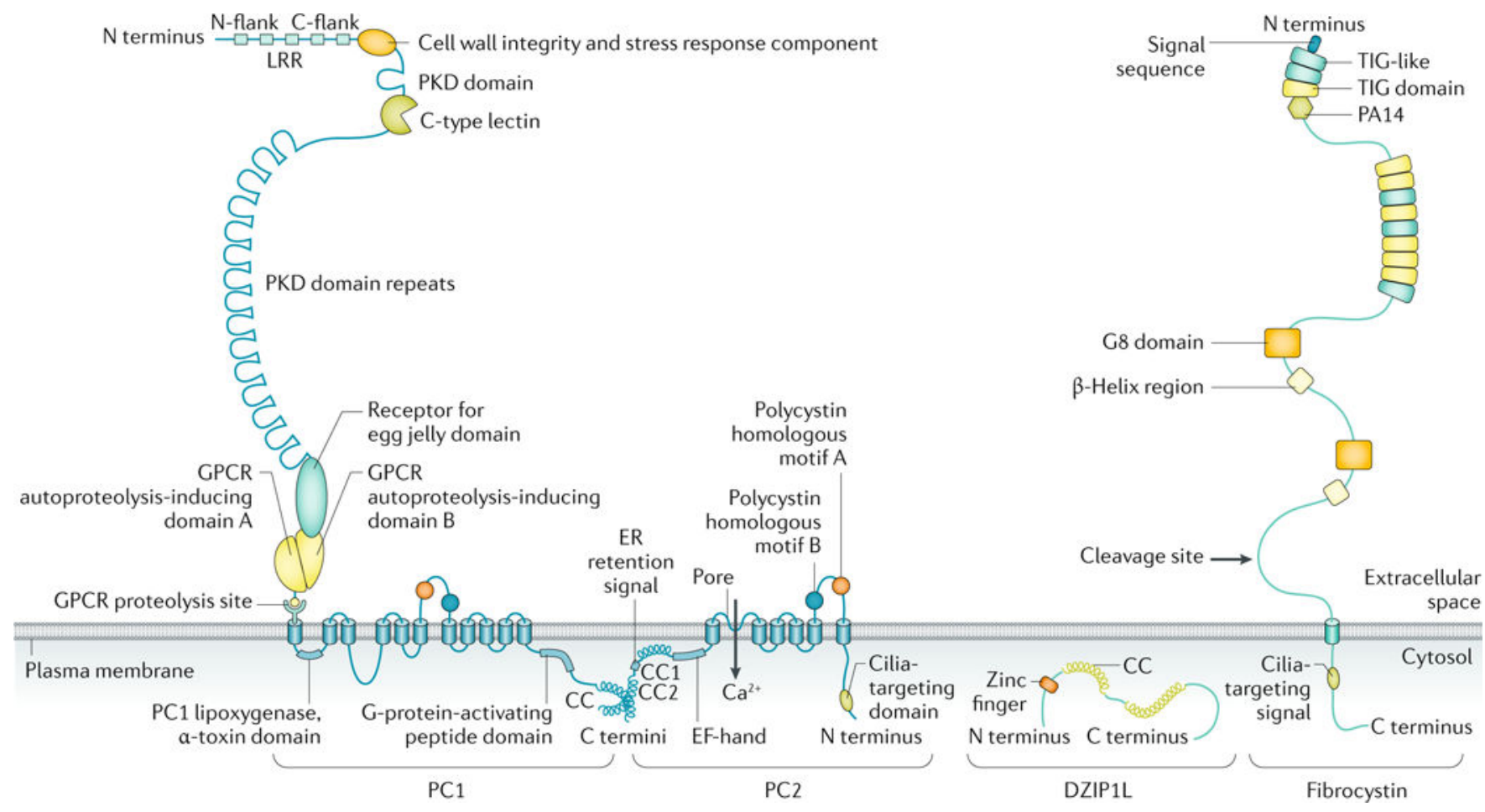

Fig. 2 |. Domain organization of proteins implicated in polycystic kidney disease.

The structure of polycystin 1 (PC1), polycystin 2 (PC2), the membrane-bound form of fibrocystin and DAZ-interacting protein 1-like protein (DZIP1L) are depicted (not to scale). PC1 and PC2 are multispan membrane proteins that form a complex that is localized to multiple subcellular locations, including the primary cilium. Fibrocystin is also localized to the primary cilium and is subject to Notch-like proteolytic processing, resulting in release of the carboxy-terminal tail, which can translocate to the nucleus and may regulate gene expression. DZIP1L is a soluble zinc-finger protein that is localized to the centrioles and basal bodies at the ciliary transition zone. CC, coiled coil; $\mathrm{C}$ flank, carboxyl flank; $\mathrm{C}$ terminus, carboxyl terminus; ER, endoplasmic reticulum; GPCR, G protein-coupled receptor; LRR, leucine-rich repeat; $\mathrm{N}$ flank, amino flank; $\mathrm{N}$ terminus, amino terminus; PKD, polycystic kidney disease. Adapted from REF. ${ }^{293}$, Springer Nature Limited. 


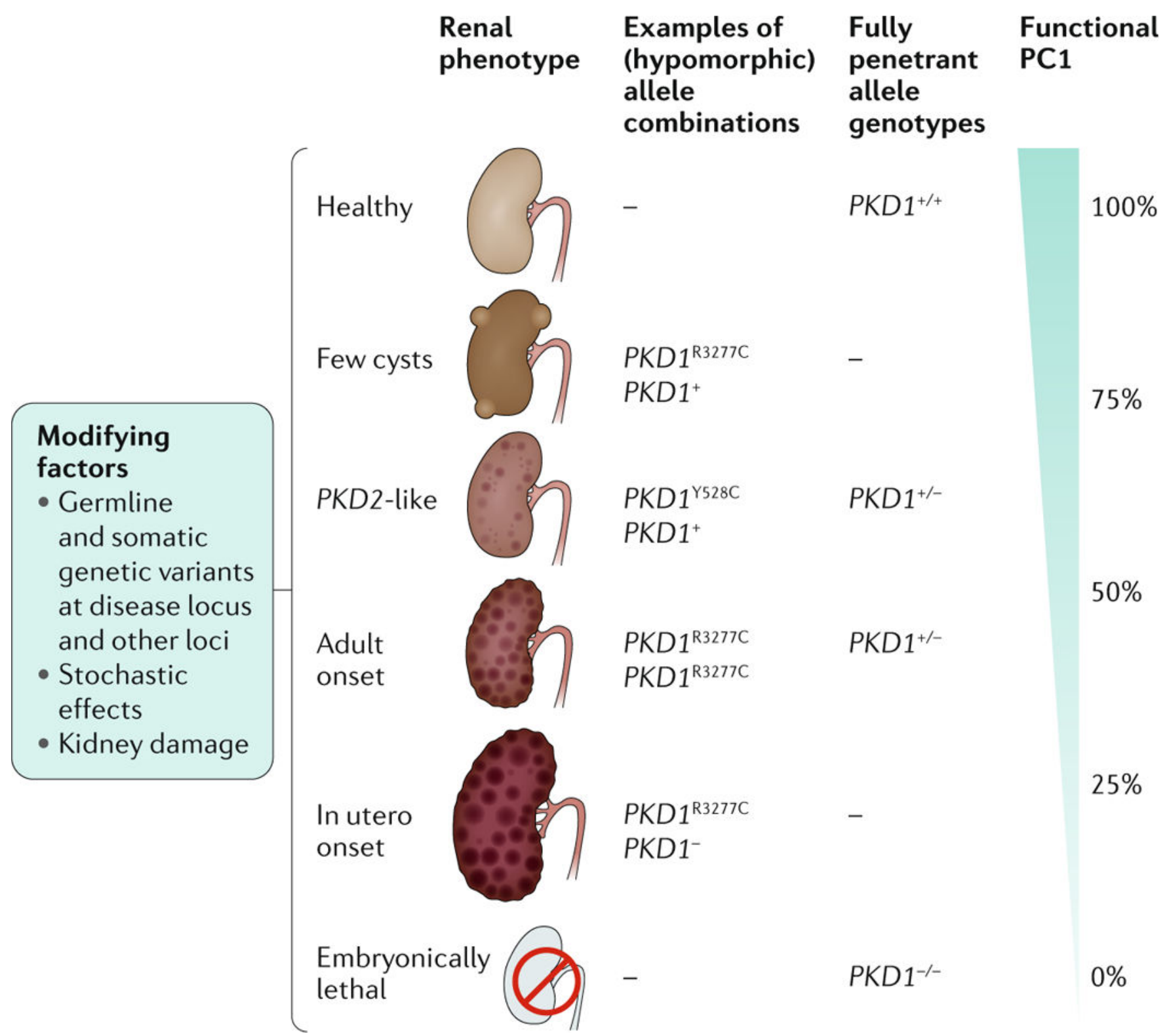

Fig. 3 |. The dosage model of cystogenesis in autosomal dominant polycystic kidney disease. The level of functional polycystin 1 (PC1; encoded by PKD1) directly influences the renal phenotype in patients with autosomal dominant polycystic kidney disease (ADPKD) - an $\sim 50 \%$ reduction in PC1 levels (for example, from haploinsufficiency due to a single inactivating allele) is associated with adult-onset PKD, whereas the complete absence of PC1 is lethal. Furthermore, incompletely penetrant (hypomorphic) PKD1 alleles of different strengths and combinations also influence the renal phenotype. For example, the PKD1 $1^{\mathrm{S} 28 \mathrm{C}}$ allele results in a phenotype similar to that in patients with mutations in $P K D 2$, whereas the $P K D 1^{\mathrm{R} 3277 \mathrm{C}}$ allele can result in a phenotype that ranges in severity from just a few cysts to adult-onset disease to early-onset disease, depending on which $P K D 1$ allele is present in trans. Additional mutations and/or variants of the disease-causing locus and somatic and germline mutations at other loci, as well as chance and environmental factors, influence the 
disease course by determining the frequency of cyst development and their progression. Adapted with permission from REF. ${ }^{294}$, Elsevier. 

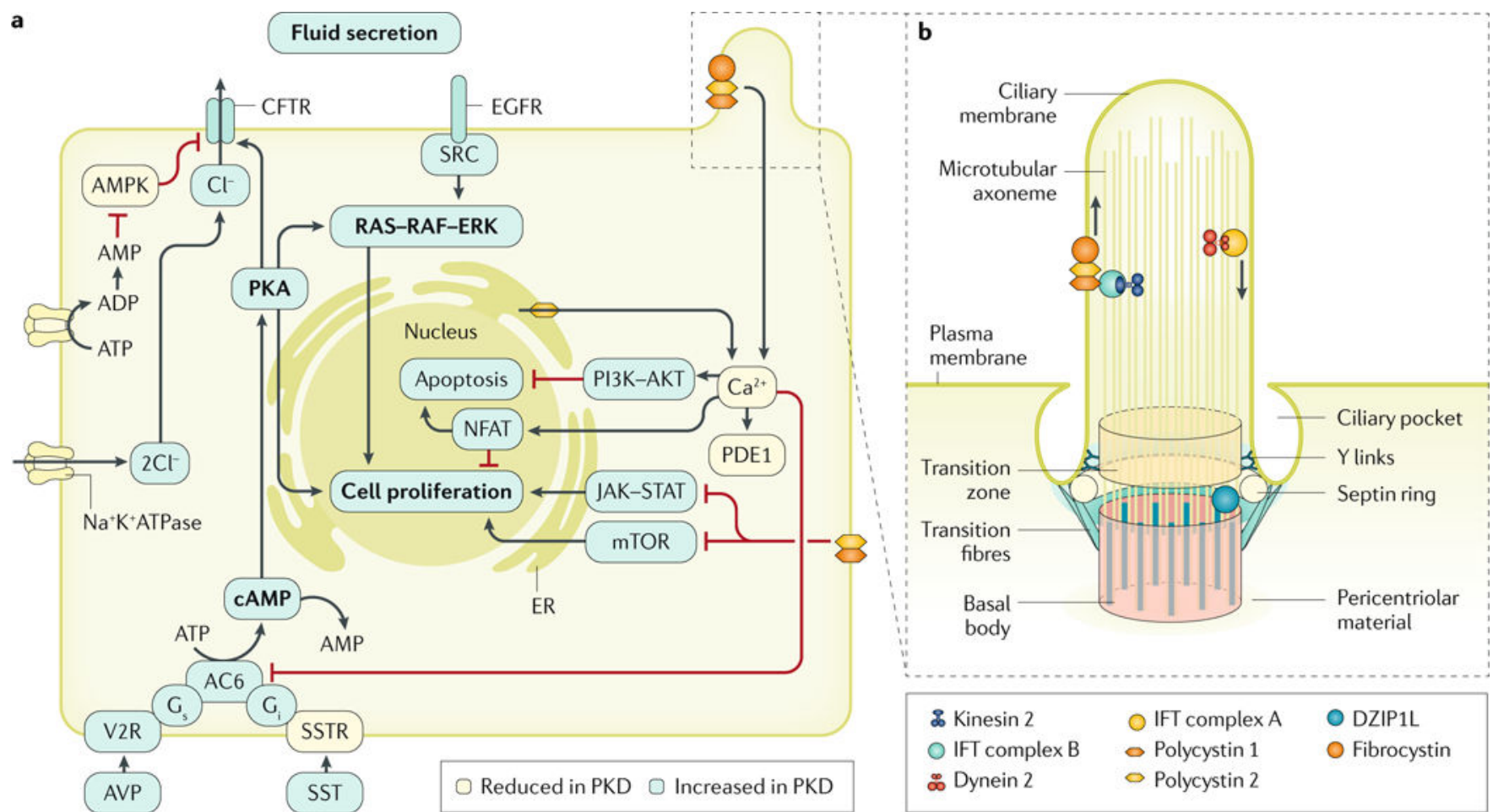

Fig. 4 |. Mechanisms of cyst formation and expansion.

Polycystin 1 (PC1) and PC2 form a multimeric protein complex that is localized to several cellular compartments, including cell-cell junctions, cell-matrix interfaces and in the primary cilium (part $\mathbf{a}$; the ciliary localization of the polycystins is shown in part $\mathbf{b}$ ). The polycystin proteins are also post-translationally modified, which regulates their transport, localization and/or function $52,121,288,295$. In addition, many proteins have been reported to bind directly to polycystin proteins; for example, PC1 and fibrocystin bind to PC2 and modulate its channel activity $53,296,297$. Furthermore, DAZ-interacting protein 1-like protein (DZIP1L) interacts with septin 2 (SEPT2; in the septin ring), a protein implicated in maintenance of the periciliary diffusion barrier at the ciliary transition zone. Consistent with a defect in the diffusion barrier, the localization of PC1 and PC2 to the ciliary membrane is compromised in DZIP1L-mutant cells, suggesting that DZIP1L is required for regulating the integrity of the transition zone. How PC1, PC2, fibrocystin and DZIP1L directly affect cellular signalling is not known with certainty. However, these proteins modulate several signalling pathways, which in turn control essential cellular functions, such as proliferation, apoptosis, cell adhesion and differentiation ${ }^{54}$. Reduced $\mathrm{Ca}^{2+}$ influx, increased cAMP levels and aberrant activation of RAS-RAF-ERK signalling in renal epithelial cells are important mediators of cyst growth. Other proposed mechanisms that regulate cystogenesis and/or cyst growth include altered signalling mediated by $\mathrm{G}$ proteins, mechanistic target of rapamycin (mTOR), phosphoinositide 3-kinase (PI3K)-AKT, AMP-activated protein kinase (AMPK), Janus kinase 2 (JAK2)-signal transducer and activator of transcription 1 (STAT1; or STAT3 or STAT6), nuclear factor of activated T cells (NFAT) and nuclear factor- $\mathrm{kB}$. In addition, cyst expansion is accompanied by changes in cellular metabolism, such as a switch to aerobic glycolysis as well as impaired fatty acid oxidation. AC6, adenylyl cyclase 6; AVP, arginine vasopressin; CFTR, cystic fibrosis transmembrane conductance regulator; EGFR, 
epidermal growth factor receptor; ER, endoplasmic reticulum; IFT, intraflagellar transport; PDE1, phosphodiesterase 1; PKA, protein kinase A; PKD, polycystic kidney disease; SST, somatostatin; SSTR, somatostatin receptor; V2R, vasopressin V2 receptor.Part $\mathbf{a}$ is adapted from REF. ${ }^{293}$, Springer Nature Limited. Part $\mathbf{b}$ is adapted from REF. ${ }^{298}$, Springer Nature Limited. 


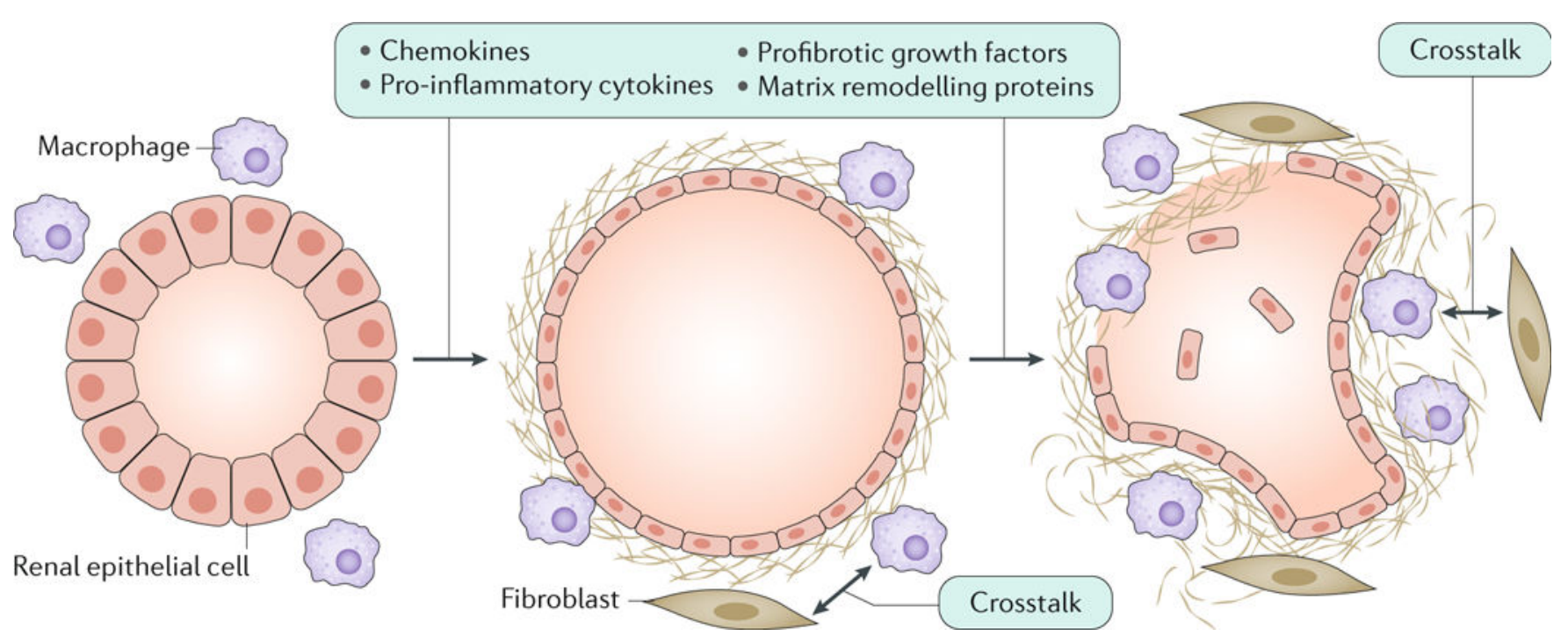

Fig. $5 \mid$. Renal fibrosis in autosomal dominant polycystic kidney disease.

Altered expression of cystic proteins and dysregulated signalling in renal epithelial cells affect cell-extracellular matrix interactions and induce the production of chemokines (such as monocyte chemotactic protein 1 (MCP1), CC-chemokine ligand 6 (CCL6), CCL28, CXCchemokine ligand 1 (CXCL1), CXCL8 and $\mathrm{CX}_{3} \mathrm{C}$-chemokine ligand 1 (CX3CL1)), proinflammatory cytokines (such as tumour necrosis factor (TNF), IL-1, IL-2, IL-6, IL-8, macrophage colony-stimulating factor 1 (CSF1) and macrophage migration inhibitory factor (MIF)), profibrotic growth factors (such as transforming growth factor- $\beta$ (TGF $\beta$ ), TGFa, epidermal growth factor (EGF), fibroblast growth factors (FGFs) and platelet-derived growth factor (PDGF)) and proteins involved in matrix remodelling (such as matrix metalloproteinases (MMPs) and tissue inhibitors of metalloproteinases (TIMPs) $)^{299,300 .}$ These changes result in the accumulation of extracellular matrix and the recruitment of inflammatory cells, which is already observed in the early stages of the disease. In particular, M1 and M2 macrophages are important contributors to disease progression. Macrophages and interstitial fibroblasts also produce cytokines, and abnormal cytokine-mediated crosstalk between renal epithelial cells and inflammatory cells results in a positive feedback loop of increasing fibrosis. 
a
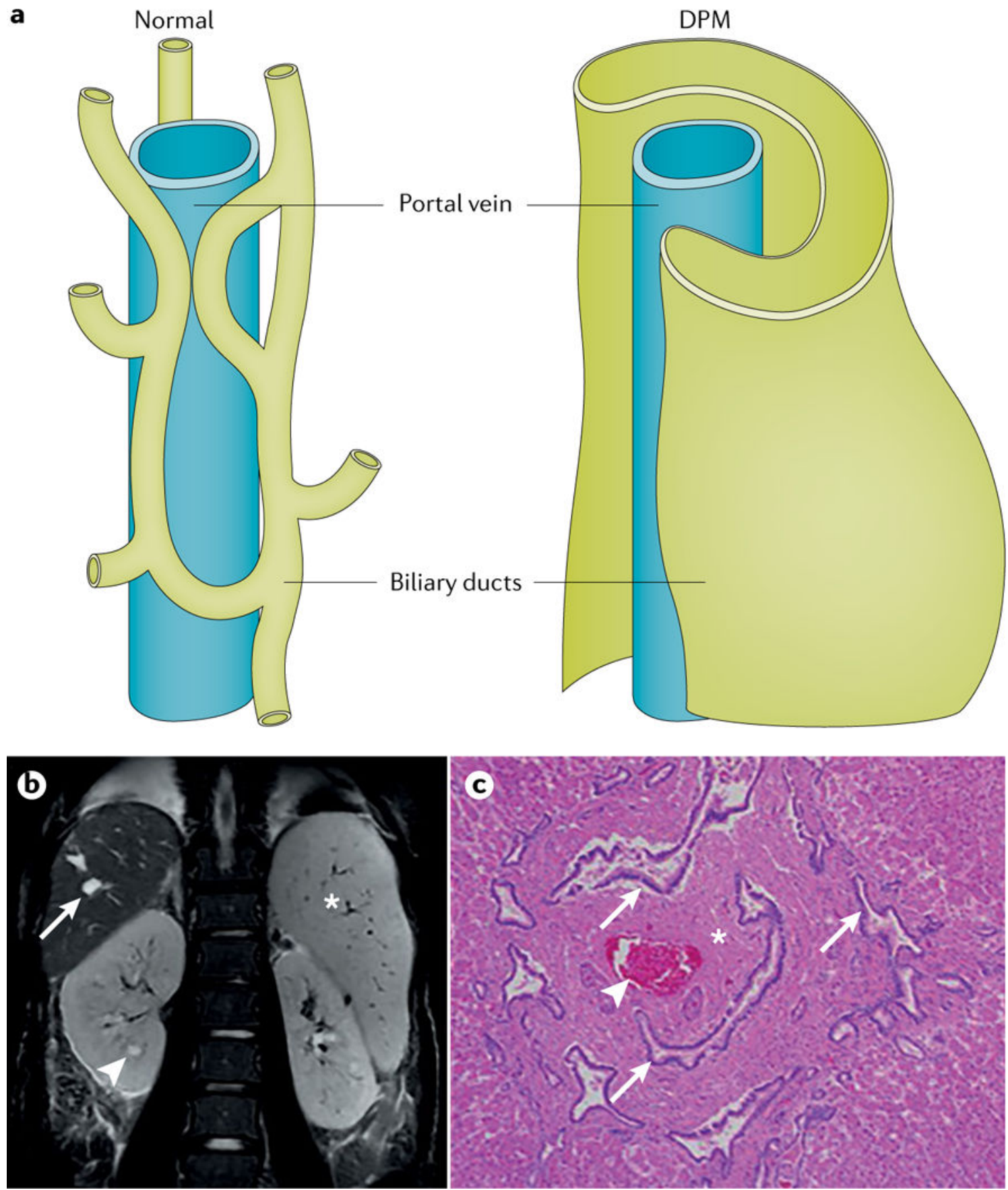

Fig. 6 |. Hepatobiliary lesions in hepatorenal disease.

a Hepatobiliary lesions result from an architectural defect in the developing biliary tree. The normal ramifications of the portal venous system and the lattice-like network of associated biliary ducts (left) are disrupted owing to ductal plate malformation (DPM) (right), likely owing to a defect in terminal differentiation of cholangiocytes. b| The DPM results in marked cystic and fusiform dilatation of the intrahepatic biliary system (coronal T2-weighted image of the abdomen), nephromegaly with small cysts (arrowhead), cystic biliary disease (arrow) and marked splenomegaly (asterisk). c| The histopathological 
manifestation of the DPM is congenital hepatic fibrosis (section stained with haematoxylin and eosin), which is characterized by extensive fibrosis of the portal area (asterisk), ectatic, tortuous bile ducts (arrows) and hypoplasia of the portal vein (arrowhead). Magnification is 40x. Part a is reprinted, with permission, from Marchal G J, Desmet V J, Proesmans W C, et al. Caroli disease: high-frequency US and pathologic findings. 



Fig. 7 |. Diagnosis of autosomal dominant polycystic kidney disease using different imaging techniques.

a-b | Comparison of MRI (T2; part a) and CT (without contrast; part b) scans of a 35-yearold woman with autosomal dominant polycystic kidney disease (ADPKD), showing widespread kidney cysts and a few liver cysts. c-e | T2 MRI images of patients with ADPKD who have a truncating mutation in $P K D 1$ (part $\mathbf{c}$; 41-year-old man), a nontruncating mutation in $P K D 1$ (part $\mathbf{d}, 40$-year-old man) or a splicing mutation in $P K D 2$ (part e; 41-year-old man). Patients with truncating mutations in $P K D 1$ typically have more cysts, whereas patients with non-truncating mutations in $P K D 1$ have an intermediate number of cysts and patients with splicing mutations in $P K D 2$ have the fewest cysts. 


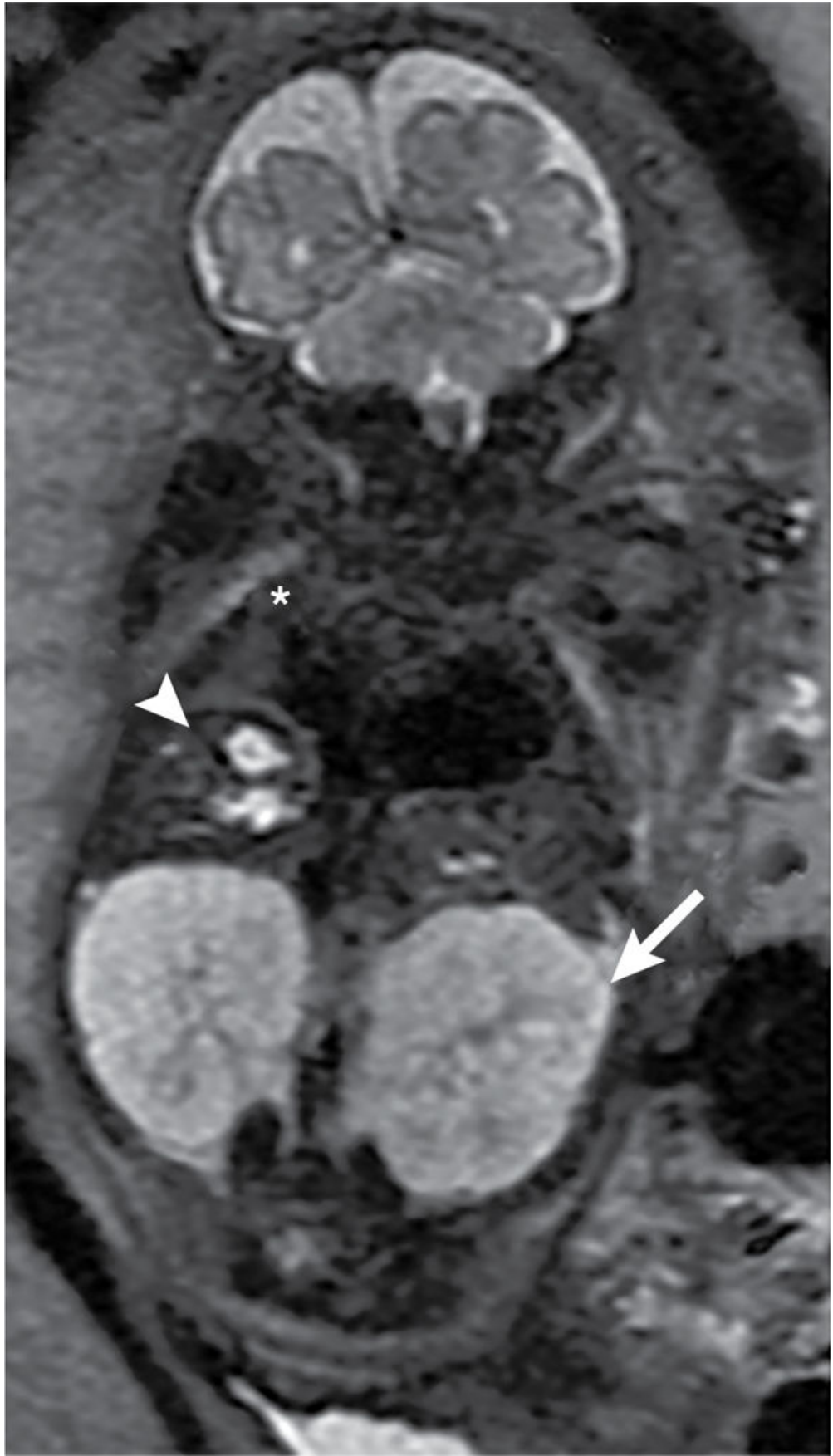

Fig. 8 |. Diagnosis of autosomal recessive polycystic kidney disease using MRI.

MRI can be used to detect renal and extrarenal manifestations of autosomal recessive polycystic kidney disease (ARPKD). In this coronal, T2-weighted MRI scan of a 32-weekold fetus, the kidneys (arrow) are massively enlarged and are abnormally bright with innumerable tiny cysts, most of which cannot be individually resolved. Cystic biliary disease (arrowhead) and extremely low lung volumes (asterisk) in patients with ARPKD are due to oligohydramnios (deficiency of amniotic fluid). 


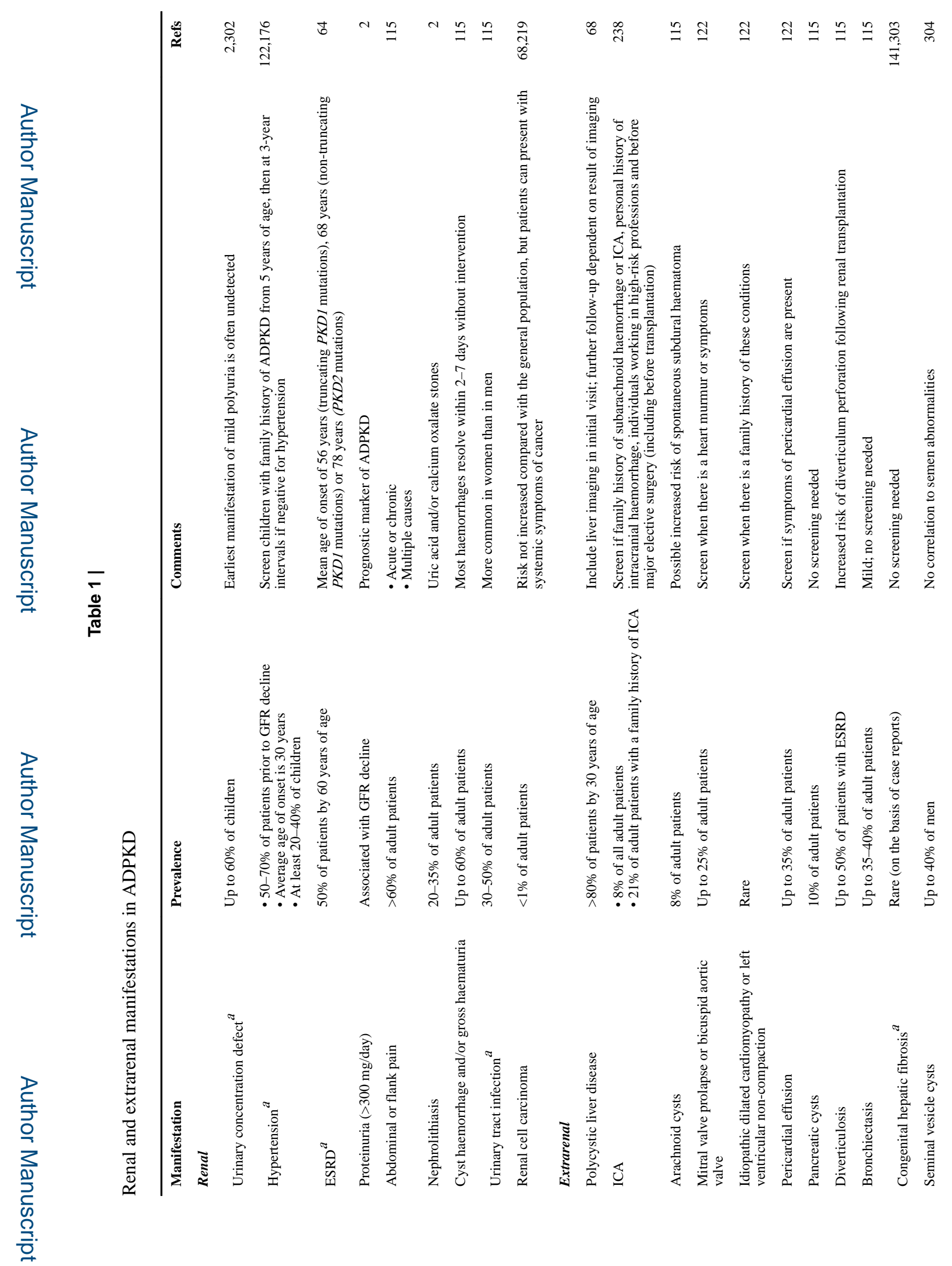

Nat Rev Dis Primers. Author manuscript; available in PMC 2019 June 25. 


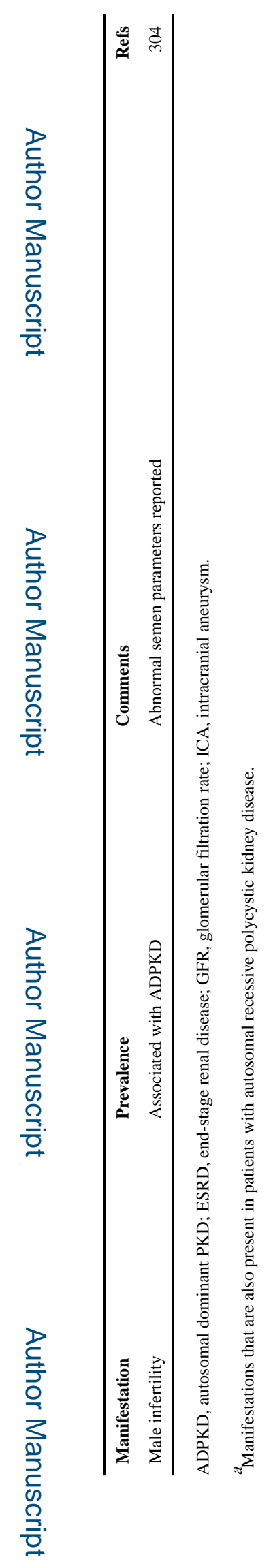

Nat Rev Dis Primers. Author manuscript; available in PMC 2019 June 25. 
Table 2 |

Ultrasonography criteria for an ADPKD diagnosis in at-risk individuals

\begin{tabular}{|c|c|c|c|}
\hline \multirow[t]{2}{*}{ Age } & \multicolumn{3}{|l|}{ Genotype } \\
\hline & PKD1 mutation & PKD2 mutation & $\begin{array}{l}\text { Unknown ADPKD } \\
\text { genotype }\end{array}$ \\
\hline $15-30$ years & $\begin{array}{l}\text { - } \geq 3 \text { cysts }^{a} \\
\text { - } \mathrm{PPV}=100 \% \\
\text { - } \mathrm{SEN}=94.3 \%\end{array}$ & $\begin{array}{l}\text { - } \geq 3 \text { cysts }^{a} \\
\text { - } \mathrm{PPV}=100 \% \\
\text { - } \mathrm{SEN}=69.5 \%\end{array}$ & $\begin{array}{l}\text { - } \geq 3 \text { cysts }^{a} \\
\text { - } \mathrm{PPV}=100 \% \\
\text { - } \mathrm{SEN}=81.7 \%\end{array}$ \\
\hline 30-39 years & $\begin{array}{l}\text { - } \geq 3 \text { cysts }^{a} \\
\text { - } \mathrm{PPV}=100 \% \\
\text { - } \mathrm{SEN}=96.6 \%\end{array}$ & $\begin{array}{l}\text { - } \geq 3 \text { cysts }^{a} \\
\text { - } \mathrm{PPV}=100 \% \\
\text { - } \mathrm{SEN}=94.9 \%\end{array}$ & $\begin{array}{l}\text { - } 23 \text { cysts }^{a} \\
\text { - } \mathrm{PPV}=100 \% \\
\text { - } \mathrm{SEN}=95.5 \%\end{array}$ \\
\hline $40-59$ years & $\begin{array}{l}\text { - } \geq 2 \text { cysts in each kidney } \\
\text { - } \mathrm{PPV}=100 \% \\
\text { - } \mathrm{SEN}=92.6 \%\end{array}$ & $\begin{array}{l}\text { - } \geq 2 \text { cysts in each kidney } \\
\text { - } \mathrm{PPV}=100 \% \\
\text { - } \mathrm{SEN}=88.8 \%\end{array}$ & $\begin{array}{l}\text { - } \geq 2 \text { cysts in each kidney } \\
\text { - } \mathrm{PPV}=100 \% \\
\text { - } \mathrm{SEN}=90 \%\end{array}$ \\
\hline
\end{tabular}

Compiled with data from Ref. ${ }^{161}$. ADPKD, autosomal dominant polycystic kidney disease; PPV, positive predictive value; SEN, sensitivity.

${ }^{a}$ Unilateral or bilateral. All values are mean estimates. 